\title{
Down-regulation of miR-205 promotes stemness of hepatocellular carcinoma cells by targeting PLC $\beta 1$ and increasing CD24 expression
}

\author{
J. ZHAO ${ }^{1}$, G. XU'², Y. WANG ${ }^{3}$, D. QIAN ${ }^{4}$, Y. WANG ${ }^{5}, Y . X . \mathrm{LI}^{1, \star}$
}

${ }^{1}$ Department of General Surgery, The First Affiliated Hospital of Anhui Medical University, Hefei 230032, China; ${ }^{2}$ Department of Gastroenterology, Drum Tower Hospital Affiliated to Medical School of Nanjing University, Nanjing 210008, China; ${ }^{3}$ Department of Oncology, Wuhu No.2 People's Hospital, 259 Jiuhua Middle Road, Wuhu, 241001, Anhui Province, China; ${ }^{4}$ Department of Oncology, Nanjing Red Cross Hospital,242 Baixia Road, Nanjing 210001, Jiangsu Province, China; ${ }^{5}$ Department of Respiratory Medicine, Drum Tower Hospital Affiliated to Medical School of Nanjing University, Nanjing 210008, China

*Correspondence: yongxiangli_1@hotmail.com

Received October 12, 2014 / Accepted January 7, 2015

\begin{abstract}
Hepatocellular carcinoma (HCC) is a particularly lethal form of cancer. Overall survival eve after liver surgery is unsatisfactory due to high metastatic capacity and recurrence rates. Cancer stem cells (CSCs) were recently proposed to elucidate the molecular mechanism of HCC metastasis and recurrence. In our study, we found that down-regulation of miR-205 promoted stem cell inhibition of HCC.

Expression of miR-205 and PLC $\beta 1$ was investigated by qRT-PCR. MiR-205 and PLCB1 expression were associated with disease free survival(DFS) by log-rank test. Computational predicting software was used to predict potential targets of miR205. MiR-205 and PLC $\beta 1$ were transfected into cells to analyze the stem cell inhibition.

MiR-205 was significantly down-regulated and PLC $\beta 1$ dramatically up-regulated in tumors compared with matched tissues $(\mathrm{P}<0.0001)$. High miR-205 and low PLC $\beta 1$ expression was found to be associated with better DFS. PLC $\beta 1$ was one of the potential targets of miR-205 and the dual luciferase report system demonstrated that PLC $\beta 1$ was a direct target of miR-205 in cells. When miR-205 and PLC $\beta 1$ were transfected into cells, we found that the number of spheres increased and the CD24+ subpopulation of HCC cells dramatically increased.

Down-regulation of miR-205 promotes stem cell inhibition of HCC by targeting PLC $\beta 1$ and increasing CD24 expression.
\end{abstract}

Key words: miR-205, HCC, PLCB1, stem cell inhibition

Hepatocellular carcinoma (HCC) is the sixth most common malignancy and globally the third-leading cause of cancer-related death [1]. The incidence of HCC is dramatically increasing in developing countries such as China, in which hepatitis B virus (HBV) infection is prevalent, and HBV has been shown to be closely associated with hepatocarcinogenesis $[2,3]$. Due to the often late diagnosis and lack of effective treatment, most HCC develops to the advanced stages, where surgery is not an option, which generally results in poor prognosis [4]. Thus, more effective treatments are urgently needed for HCC. Cancer stem cells (CSCs), also known as tumorinitiating cells, have been demonstrated in HCC cells and are considered the master regulators of HCC initiation, metastasis and chemotherapeutic drug resistance [5-7]. Hence, hepatic CSCs may serve as better therapeutic targets for treating HCC patients. Despite the clinical importance, the regulation of hepatic CSCs remains elusive.

MicroRNAs (miRNAs), the small endogenous non-coding RNA, play an important role in modulating diverse cellular processes including growth, differentiation and apoptosis, by targeting the protein coding genes or even long noncoding RNAs [8]. Thus, the discovery of miRNAs extends our knowledge about gene expression and regulation. It is estimated that approximately one third of all human genes are regulated by miRNAs [9]. Recent evidence has highlighted the function of miRNAs in modulating and controlling the self-renewal and pluripotency of stem cells [10]. Currently, some miRNA clusters, which are highly expressed in embryonic stem cells, have been shown to promote induced pluripotent stem cells (iPS cells) reprogramming [11]. For instance, miR-134, miR-296, 
and miR-470 significantly increased during the differentiation of mouse embryonic stem cells [12]. In HCC, the modulation of hepatic CSCs is largely unknown. Some evidence has shown that miRNAs and other noncoding RNAs play important roles in the regulation of hepatic CSCs.

In order to elucidate the role of miR-205 in the regulation of hepatic CSCs in HCC cells, we first analyzed the expression of miR-205 in HCC tumors and matched normal tissues and found that miR-205 was significantly down-regulated in HCC tumors. Moreover, when these patients were followed-up after surgery, we found that the down-regulation of miR-205 was closely associated with longer disease free survival (DFS), indicating that it could be a prognostic biomarker in HCC. We further demonstrated that phospholipase $C \beta 1$ (PLC $\beta-1)$ was one of the potential targets of miR-205 using online predicting software and remained the downstream target in cells. PLC $\beta-1$ was also closely related to the DFS when patients underwent surgery. When PLC $\beta-1$ and miR-205 were transfected into HCC cells, we found that they could regulate the stem cell inhibition of HCC by increasing the CD24+ cell population. Taken together, miR-205 can regulate the stem cell inhibition of HCC by targeting PLC $\beta-1$ and can also be a prognostic biomarker of HCC in clinical settings.

\section{Materials and methods}

Reagents and cell culture. The human HCC cell lines were cultured in modified RPMI-1640 or DMEM (Invitrogen, Carlsbad, CA, USA) with $10 \%$ fetal bovine serum (FBS) and $100 \mathrm{units} / \mathrm{mL}$ of penicillin and $100 \mu \mathrm{g} / \mathrm{mL}$ of streptomycin (GIBCO, Grand Island, NY, USA). The SuperScript III First-Strand Synthesis System kit for RT-PCR was purchased from Life Technologies (Carlsbad, CA, USA). The SsoFast ${ }^{\mathrm{tm}}$ EvaGreen ${ }^{\circ}$ Supermix for qPCR was from Bio-Rad (Hercules, CA, USA). The HCC tumors and matched normal tissues were obtained from and the Department of General Surgery, the First Affiliated Hospital of Anhui Medical University. The informed consents were obtained from patients and this study was approved by the ethics committee of Anhui Medical University.

RNA extraction and Real-Time Quantitative ReverseTranscription PCR (qRT-PCR). Total RNA from HCC tumors or matched normal tissue samples or cell lines was extracted using TRIzol reagent (Life Technologies, USA). The quality and quantity of isolated total RNA was assessed using the NanoDrop ND-1000 Spectrophotometer. For mRNA detection, the total RNA was reverse-transcribed using the SuperScript III First-Strand Synthesis System kit and then amplification was performed using the SsoFast ${ }^{\mathrm{tm}}$ EvaGreen ${ }^{\circ}$ Supermix. The primers for PLC $\beta 1$ were 5'GGGGTACCCCAAATGCTTGTCTGGCCTCC-3'(F), and 5'-GCTCTAGAGCCTGGTGAACTATATTCAGCC-3'(R)[13]; The primers for HPRT1 were TGACACTGGCAAAACAATGCA (F) and GGTCCTTTTCACCAGCAAGCT (R). For miRNA detection, the total RNA was polyadenylated and reverse-transcribed for quantitative RT-PCR using the NCode $^{\text {tu }}$ VILO $^{\text {ma }}$ miRNA cDNA Synthesis and EXPRESS SYBR $^{\circ}$ GreenER ${ }^{\mathrm{Tw}}$ miRNA qRT-PCR kits (Life Technologies, USA), according to the manufacturer's instructions. HPRT1 and U6 internal control were used as endogenous controls, and fold changes were calculated via relative quantification $\left(2^{-\Delta C t}\right)$.

Western blotting. The transfected cells were washed twice with cold PBS and solubilized in radioimmunoprecipitation assay (RIPA) lysis buffer with the halt protease inhibitor cocktail (Pierce, Rockford, IL, USA). The protein concentrations were determined using the Bradford protein assay (BioRad, Hercules, CA, USA). Heat-denatured protein samples (20 $\mu \mathrm{g}$ per lane) were resolved by SDS-polyacrylamide gel electrophoresis (PAGE) and transferred to the nitrocellulose membrane using the iBlot ${ }^{\oplus}$ Dry blotting transfer system (Life Technologies, USA). The membrane was incubated for $2 \mathrm{~h}$ in PBS containing $0.1 \%$ Tween 20 and 5\% skimmed milk to block non-specific binding, followed by incubation overnight at $4^{\circ} \mathrm{C}$ with a primary rabbit polyclonal antibody against PLC $\beta 1$ (1:500 dilution) (Abcam, UK) or goat anti-GAPDH polyclonal antibody (1:1000) (GenScript, NJ). The membrane was washed three times for 10 min each in PBS with $0.1 \%$ Tween 20 and then incubated for 1-2 $\mathrm{h}$ with the secondary antibody. The membrane was washed thoroughly in PBS containing $0.1 \%$ Tween 20 and subjected to Pierce ECL Western blotting (Pierce, Rockford, IL), according to the manufacturer's instructions.

Sphere formation assay. Single-cells $\left(1 \times 10^{3}\right)$ were plated onto a 24-well ultralow-attachment plate (Corning, Corning, $\mathrm{NY}$ ) in serum-free DMEM-F12, supplemented with $10 \mathrm{ng} /$ $\mathrm{mL}$ basic fibroblast growth factor, $20 \mathrm{ng} / \mathrm{mL}$ epidermal growth factor, $0.4 \%$ bovine serum albumin and B-27 supplement (1:50 dilution; Invitrogen). After 14 days of culture, the number of formed tumor spheres (diameter $>40 \mu \mathrm{m}$ ) were counted under an inverted microscope.

Flow cytometry. Stably transfected cells $\left(1 \times 10^{6}\right)$ were resuspended in $100 \mu \mathrm{l}$ of staining buffer (eBioscience, San Diego, CA) containing $1 \% \mathrm{FBS}$ and placed on ice for $20 \mathrm{~min}$ to block $\mathrm{Fc}$ receptors. After incubation with primary phycoerythrinconjugated anti-human CD24 antibodies (BD Biosciences, USA) for another $45 \mathrm{~min}$ on ice in the dark, cells were washed twice with $1 \mathrm{ml}$ ice-cold staining buffer and centrifuged at $400 \times \mathrm{g}$ for $5 \mathrm{~min}$ at $4^{\circ} \mathrm{C}$. Cells resuspended in $0.5 \mathrm{ml}$ of $2 \%$ formaldehyde fixation buffer were analyzed using theBD FACSCanto II flow cytometer (BD Biosciences, USA) and FlowJo software. All flow cytometry results were obtained from two independent experiments performed in triplicate.

Luciferase reporter assay. The potential microRNAs targeting PLC $\beta 1$ were selected by bioinformatic analysis. The 3'-UTR sequence of PLC $\beta 1$, which is predicted to interact with the microRNAs, was synthesized and inserted into the XbaI and FseI sites of the pGL3 control vector (Promega, Madison, WI). For the reporter assay, HEK293 cells were plated onto 24-well plates and transfected with the above constructs and 
miR-205 mimics or mimic-controls using the Lipofectamine 3000 transfection reagent (Life Technologies, USA). A Renilla luciferase vector pRL-SV50 (Promega, Madison, WI) was also co-transfected to normalize the differences in transfection efficiency. After transfection for $48 \mathrm{~h}$, cells were harvested and assayed with the Dual-Luciferase Reporter Assay System (Promega, Madison, WI) according to the manufacturer's instructions. This experiment was performed in duplicate in three independent experiments.

Survival and statistical analysis. The experimental data are presented as the mean \pm standard deviation (SD). All statistical analyses were performed using ANOVA or a two-tailed Student's $t$ test (GraphPad Prism 5). Disease free survival (DFS) was measured from the date of hepatic resection to the date of death or the last follow-up. The survival curves were calculated using the Kaplan-Meier method and statistically compared using a log-rank test. Differences were considered statistically significant when the P-values were less than 0.05 .

\section{Results}

miR-205 is down-regulated in HCC tumors and inversely associated with the expression of PLC $\beta 1$. Since miR-205 plays an important role in HCC carcinogenesis, it is interesting to investigate the expression of miR-205 in HCC patients. The expression of miR-205 and its potential target PLC $\beta 1$ in 30 samples of HCC tumors and matched normal tissues were compared by qRT-PCR. Interestingly, miR-205 was down-regulated in HCC tumors, while it was up-regulated in matched normal tissues (Fig. 1B). Computational software was used to predict the downstream target of miR-205, and PLC $\beta 1$ was of specific interest because it was involved in signal transduction cascades that influence many cellular events, including cell cycle, tumor progression and differentiation [14]. We performed qRT-PCR to analyze the expression of PLC $\beta 1$ in tumors and matched normal tissues. Conversely, it showed down-regulation of PLC $\beta 1$ in tumors when compared to matched normal tissues (Fig. 1A). Thus, the expression of miR-205 and PLC $\beta 1$ were inversely expressed in tumors and matched normal tissues (Fig.1 A\&B). This indicates that PLC $\beta 1$ may be one of the direct targets of miR-205 in HCC tumors.

Clinical significance of miR-205 and PLC $\beta 1$ in HCC patients. To investigate the clinical significance of miR-205 and PLC $\beta 1$ in HCC patients, the expression of miR-205 in 30 examples of HCC patients was compared by qRT-PCR. Interestingly, we found that HCC patients with high miR-205 had longer DFS compared with patients with low miR-205 $(\mathrm{P}=0.034$, Student's t-test, Fig. $2 \mathrm{~B})$. Next, we detected PLC $\beta 1$ in these 30 tumor samples. Consistently, low expression of PLC $\beta 1$ was significantly correlated with longer DFS of patients $(\mathrm{P}=0.044$; Fig. 2A). In HCC, shorter DFS generally indicated that patients very often develop recurrence or metastasis and as well as resistance to chemotherapeutic therapies. Taking these results into account, miR-205, along with its downstream target- PLC $\beta 1$, may play a critical role in the development of therapeutic resistance and metastasis seen in HCC. Thus, they may serve as prognostic biomarkers or therapeutic targets for treating HCC patients.

Over-expression of PLC $\beta 1$ is associated with the loss of miR-205 in HCC. We have demonstrated the clinical significance of PLC $\beta 1$ and miR-205 in HCC; therefore, it is interesting to investigate the regulation of PLC $\beta 1$. Previous studies have suggested that at least one-third of human genes are estimated to be miRNA targets, so we used TargetScan/ TargetScanS to predict whether there is interaction between PLC $\beta 1$ and miR-205. The 3'-UTR of PLC $\beta 1$ can be perfectly matched with miR-205 (Fig.3A\&B), suggesting that PLC $\beta 1$

A

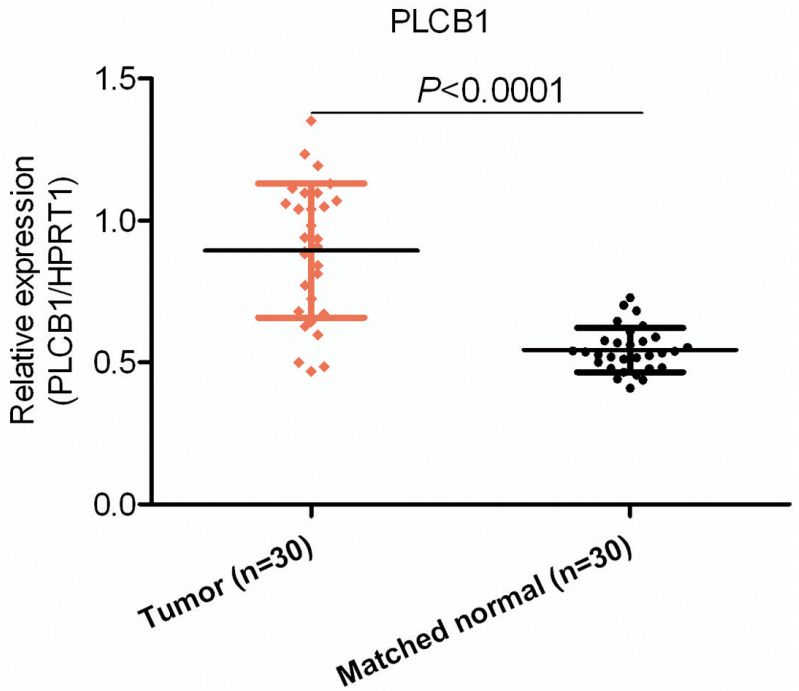

B

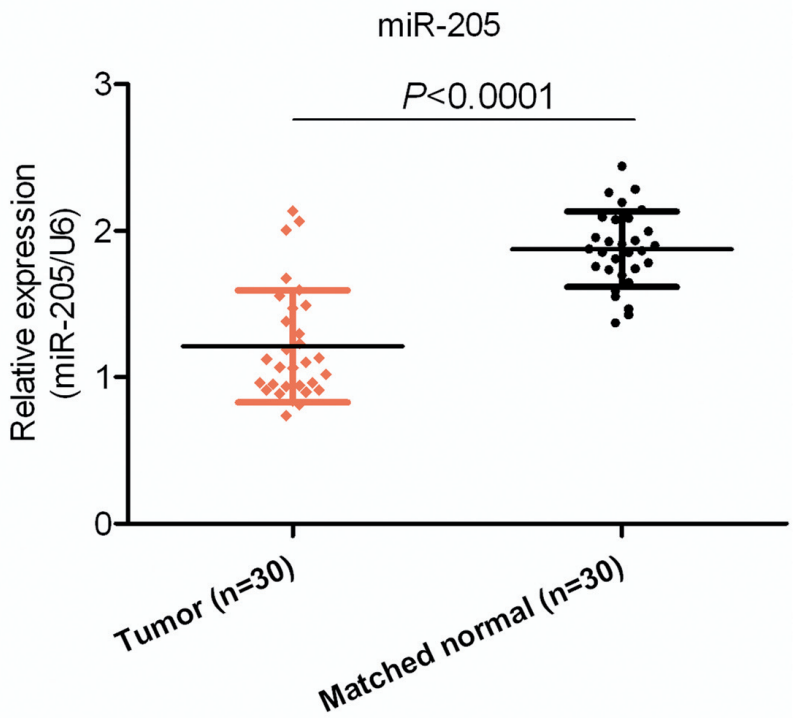

Figure 1. Overexpression of PLC $\beta 1$ was inversely associated with downregulation of miR-205 in HCC samples. (A and B) The expression of PLC $\beta 1$ (A) and miR-205 (B) in 30 pairs of HCC tissue samples was examined by real time qRT-PCR analysis. 
A

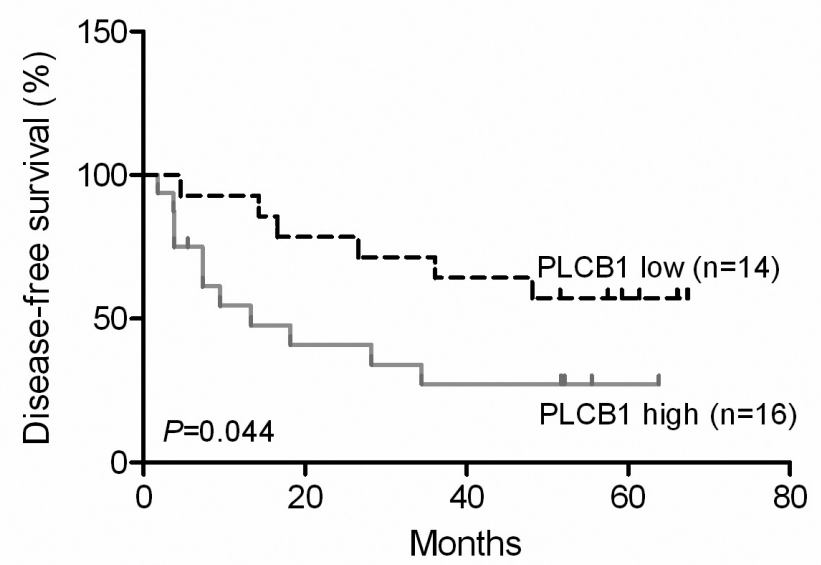

B

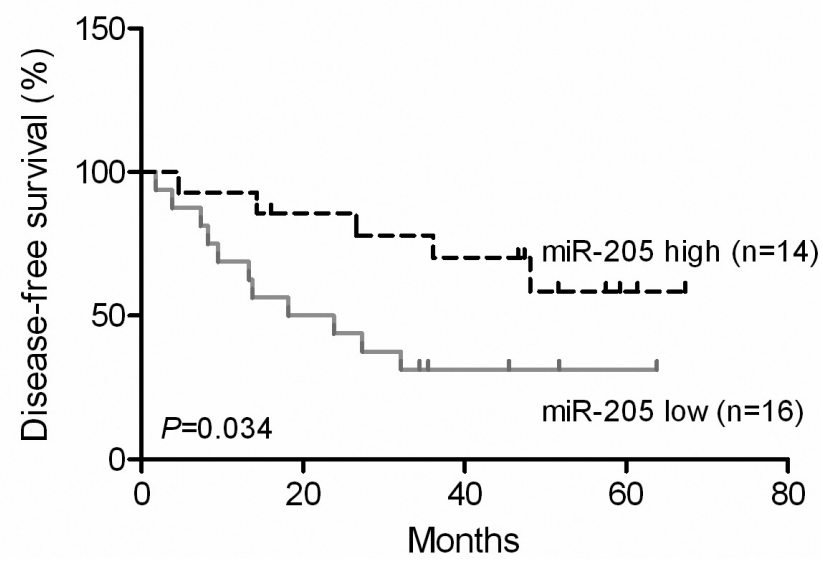

Figure 2. Overexpression of PLCB1 and down-regulation of miR-205 are associated with poor survival. (A and B) The median expression level of PLC $\beta 1$ (A) and miR-205 (B) in all 30 samples was chosen as the cut-off point. The Kaplan-Meier method was used to analyze survival in patients with HCC.

may be regulated by miR-205. To validate whether miR-205 directly recognizes the 3'-UTRs of PLC $\beta 1 \mathrm{mRNA}$, we cloned the $3^{\prime} \mathrm{UTR}$ of PLC $\beta 1$ to the pGL3 luciferase reporter gene to generate pGL3- PLC $\beta 1$-3'UTR-wt or pGL3- PLC $\beta 1$-3'UTRmut as a control vector. The vectors were then co-transfected with miR-205 plasmid or miR-205 controls into HEK293 cells. A renilla luciferase vector ( $\mathrm{pRL}-\mathrm{TK}$ ) was used to normalize differences in transfection efficiency. Luciferase activity in cells co-transfected with miR-205 and pGL3- PLC $\beta 1$-3'UTRwt vectors was decreased when compared with the control (Fig.3D). Next, we further detected the protein expression of PLC $\beta 1$ in cells after transfection with miR-205 or the control. The results showed that the over-expression of miR-205 decreased the expression of PLC $\beta 1$ (Fig. 3C). These data suggest that the over-expression of PLC $\beta 1$ is associated with a loss of miR-205 in HCC.

Overexpression of miR-205 promote stem cell inhibition of HCC cells. Recent studies have indicated that the emergence of cancer stem cells (CSCs) contributes to HCC chemoresistance, metastasis, recurrence and poor survival. Several biomarkers of HCC hepatic CSCs have been identified and CD24 is one of them. We assessed the self-renewal ability of HCC cancer cells by means of sphere formation, which is considered a hallmark of cancer stem-like cells. Interestingly, we also found that sphere formation ability was approximately 7 - to 8 -fold decreased when miR-205 was stably over-expressed in HCC cancer cells (Fig.4A and 4B). Next, we also analyzed the population of CD24+ cells, which are considered to be hepatic CSCs. Consistently, we found that when miR-205 was transfected into HCC cells, CD24+ cell number dramatically decreased compared with that when miR-205 control or both miR-205 and PLC $\beta 1$ were transfected into HCC cells. These results indicate that miR-205 promotes stemness of HCC by targeting PLC $\beta 1$ and increasing CD24 expression.

\section{Discussion}

Cancer stem cells (CSCs) compose a small fraction of tumor bulk, which show a high capacity of sphere forming, self-renewing and high resistance to chemoradiotherapy [15]. This bulk of CSCs may result in the initiation and propagation of cancer cell growth, metastasis, recurrence and chemoresistance. Targeting CSCs may represent a novel therapy for treating malignancies. Hepatic CSCs were first reported by Haraguchi and colleagues [6]. In recent studies, several biomarkers of hepatic CSCs have been identified, including CD90 [16], CD133 [17] and CD13 [18]. Another important biomarker is CD24 and CD24 positive HCC cells have been shown to be important for the maintenance, self-renewal and metastasis of HCC[19]. In our study, we found that the CD24+ cell population was increased while sphere formation capacity was also improved in stably transfected HCC cells, partly demonstrating that $\mathrm{CD} 24$ is an important biomarker for hepatic CSCs.

CSCs appear to arise by epigenetic mechanisms. MicroRNAs (miRs), 18-24nt long RNAs, have emerged as one of the most important epigenetic modulators, playing an important role in multiple biological processes such as cell growth, differentiation, apoptosis and survival[20]. The interaction between miRNAs and CSCs has been implicated in many studies. CSCs, compared with tumors or matched normal tissues, showed dramatic differently expressed miRNA patterns[21]. Furthermore, MiRNAs were proven to regulate CSCs and be crucial in maintaining CSC self-renewal and differentiation by effecting implicated signaling pathways and protein-coding genes. However, the role of a specific miRNA in CSCs maintenance or regulation is not clear. In our study, we investigated the role of miR-205 to uncover the mecha- 
A

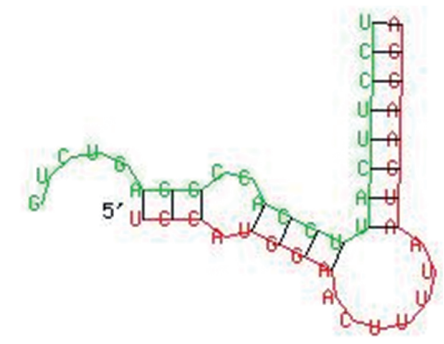

mfe: $-21.5 \mathrm{kcal} / \mathrm{mol}$

C

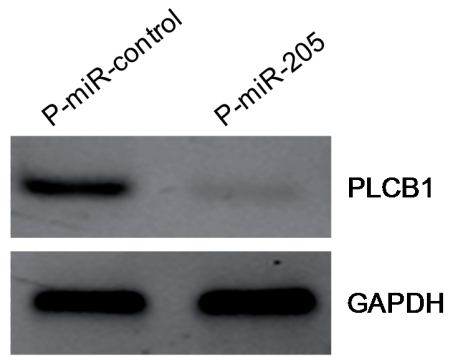

B

TargetScanHuman 6.2

miR-205 and PLCB1-3' UTR

$5^{\prime}$-UCCAUGGAACUUUUAAUGAAGGA-3' PLCB1 $-3^{\prime} \mathrm{UTR}-\mathrm{wt}$

| | | | | | | |

3' - GUCUGAGGCCACCUUACUUCCU-5' miR-205

$5^{\prime}$-UCCAUGGAACUUUUAACGACGAA-3' PLCB1-3' UTR-mut

I I | I I |

$3^{\prime}-$ GUCUGAgGCCACCUUACUUCCU-5' $\operatorname{miR}-205$

D

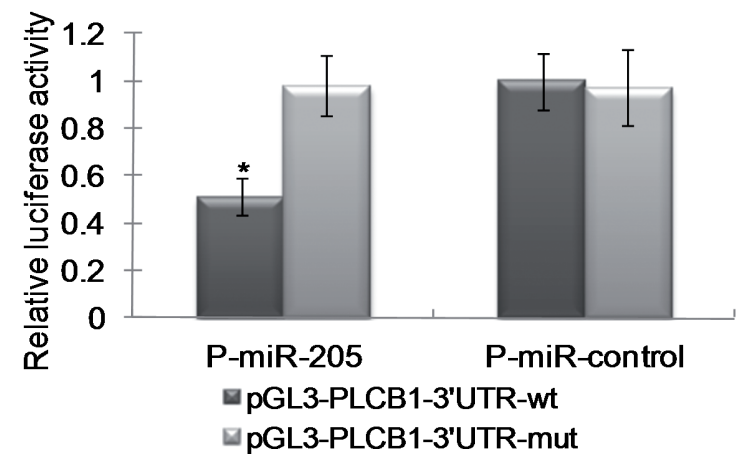

Figure 3. PLCB1 is a direct downstream target of miR-205. (A and B) The bioinformatic prediction of the binding sequence or mutation of the 3'-UTRs of PLC $\beta 1$ mRNA. (C) Western blot analysis of PLC $\beta 1$ in the cell lysates extracted from p-miR-205 or p-miR-control transfected cells. (D) Luciferase activity in cells co-transfected with p-miR-205 or p-miR-control and pGL3-PLC $\beta 1-3$ 'UTR-wt or pGL3-PLC $\beta 1$-3'UTR-mut vector.

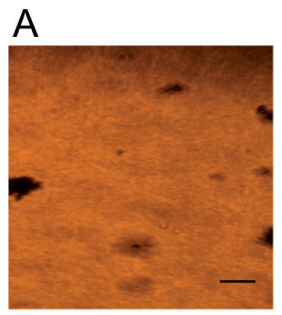

P-miR-control

C

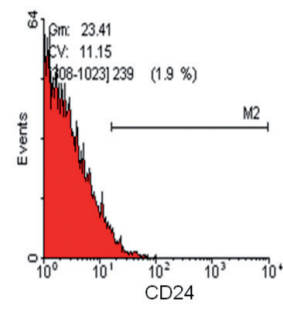

P-miR-control

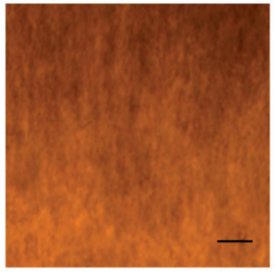

P-miR-205

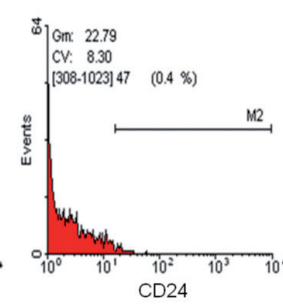

P-miR-205

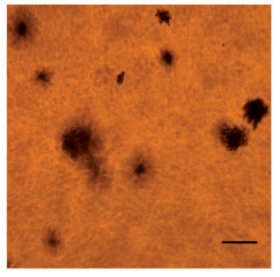

P-miR-205 $+p-P L C B 1$

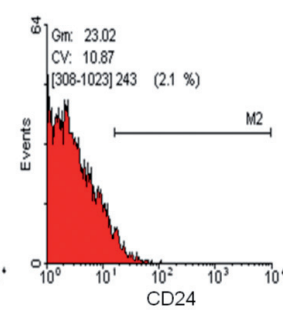

P-miR-205 $+p-P L C B 1$
B
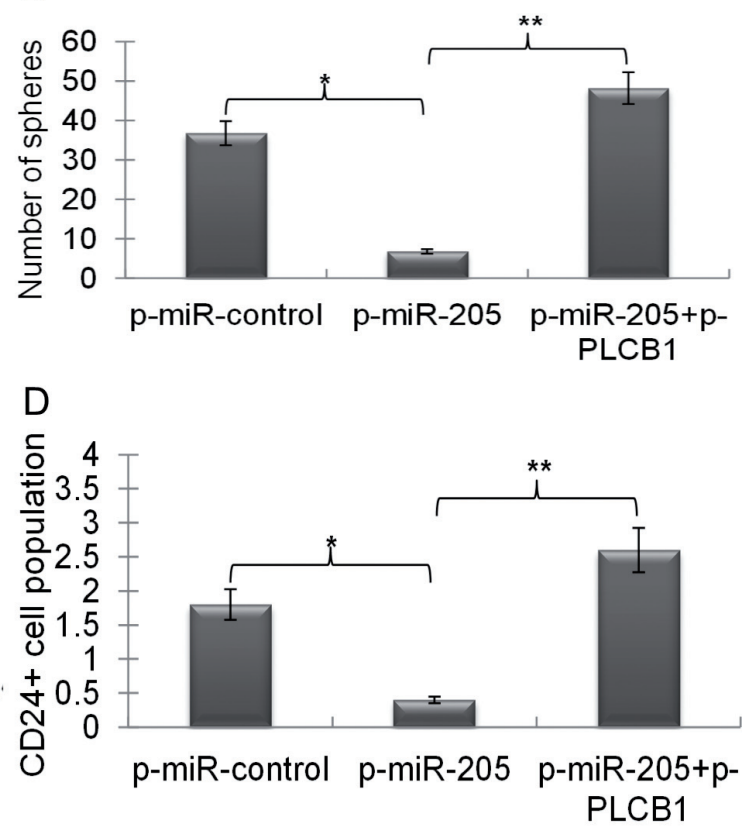

Figure 4. Down-regulation of miR-205 promotes stemness of hepatocellular carcinoma cells by targeting PLCB1 and increasing CD24 expression. (A) The representative images of tumor spheres from the sphere formation assay. (B) The bar graph indicates the number of tumor spheres (mean \pm S.D.) generated after 2-3 weeks of single-cell culture in each group. (C) Flow cytometry analysis of CD24+ cell distribution in established stable cells. (D) The bar graph indicates the quantification of $\mathrm{CD} 24+$ cell distribution in two independent experiments performed in triplicate. ${ }^{\star} P<0.05,{ }^{\star} P<0.01$ 
nism of miR-205 in the regulation or maintenance stem cell inhibition of HCC CSCs.

As many characteristics of miR-205 have been revealed, it appears to exert an effect as either an oncogenes or tumor suppressor gene, determined by the specific cancer context or its target genes [22,23]. The expression level of miR-205 is controversial as it can be down-regulated or up-regulated depending on the cell type. In our study, we found that it was down-regulated in HCC tumor tissues, indicating its role as a tumor suppressor in HCC. Previous studies have shown that it can be associated with stem cell properties in lung cancer. Consistently, we also found that miR-205 can promote stemness in HCC by targeting PLC $\beta 1$.

PLC $\beta 1$ is an important enzyme in nuclear lipid signal transduction that plays a critical role in cell cycle progression[24]. PLC $\beta 1$ presents in two forms, $150-\mathrm{kDa}$ PLC $\beta 1 \mathrm{a}$ and $140-\mathrm{kDa}$ PLC $\beta 1 \mathrm{~b}$, both of which mostly exist in the nucleus of cells. Previous studies have shown that the over-expression of PLC $\beta 1$ induces cell cycle progression by targeting cyclin D3, along with its specific kinase[25]. It was also demonstrated to regulate the expression of CD24 in mouse models[14]. In our study, comparing HCC tumor tissues and matched normal tissues, we found that PLC $\beta 1$ was significantly expressed in tumors, indicating its important role in tumorigenesis. Moreover, the computational software shows that PLC $\beta 1$ is a potential downstream target of miR205 , and the luciferase reporting system demonstrates that it is an authentic target of miR-205 in cells. Importantly, we also found that miR-205 was inversely expressed with PLC $\beta 1$ in tumor tissues. All of these results demonstrate that the miR-205/PLC $\beta 1$ axis may play an important role in HCC tumorigenesis and stemness maintenance.

We also investigated the clinical significance of miR-205 and PLC $\beta 1$ in HCC tumors. The expression of miR-205 and PLC $\beta 1$ in 30 samples of HCC was compared by qRTPCR. Interestingly, we found that HCC patients with low miR-205 or high PLC $\beta 1$ had longer disease free survival (DFS) compared with patients with high miR-205 or low PLC $\beta 1$. In HCC, shorter DFS means that patients easily developed recurrence or metastasis. From these results, it can be seen that miR-205, along with the significantly modulated PLC $\beta 1$, may play a critical role in the recurrence or metastasis of HCC. Thus, they may serve as prognostic biomarkers for HCC.

In conclusion, we found that the miR-205/PLC $\beta 1$ axis may play an important role in HCC stemness maintenance and the increased CD24 subpopulation, thus it may be a therapeutic target for the treatment of HCC in the future.

Supplementary information is available in the online version of the paper.

Acknowledgements: This study was supported by National Natural Science Foundation of China. Grant No. 82101882, 81201909

\section{References}

[1] FORNER A, LLOVET JM, BRUIX J. Hepatocellular carcinoma. Lancet 2012; 379: 1245-1255. http://dx.doi.org/10.1016/ $\underline{\text { S0140-6736(11)61347-0 }}$

[2] GOH LY, LEOW AH, GOH KL. Observations on the epidemiology of gastrointestinal and liver cancers in the Asian-Pacific region. J Dig Dis 2014; 15: 464-468. http:// dx.doi.org/10.1111/1751-2980.12164

[3] NEUVEUT C, WEI Y, BUENDIA MA. Mechanisms of HBVrelated hepatocarcinogenesis. J Hepatol 2010; 54: 594-604. http://dx.doi.org/10.1016/i.jhep.2009.10.033

[4] SCHWARTZM, ROAYAIE S, KONSTADOULAKIS M. Strategies for the management of hepatocellular carcinoma. Nat Clin Pract Oncol 2007; 4: 424-432. http://dx.doi.org/10.1038/ ncponc0844

[5] YOON SK. The biology of cancer stem cells and its clinical implication in hepatocellular carcinoma. Gut Liver 2012; 6: 29-40. http://dx.doi.org/10.5009/gnl.2012.6.1.29

[6] HARAGUCHI N, UTSUNOMIYA T, INOUE H, TANAKA F, MIMORI K, BARNARD GF, MORI M. Characterization of a side population of cancer cells from human gastrointestinal system. Stem Cells 2006; 24:506-513. http://dx.doi. org/10.1634/stemcells.2005-0282

[7] CLEVERS H. The cancer stem cell: premises, promises and challenges. Nat Med 2011; 17: 313-319. http://dx.doi. org/10.1038/nm.2304

[8] KROL J, LOEDIGE I, FILIPOWICZ W. The widespread regulation of microRNA biogenesis, function and decay. Nat Rev Genet 2010; 11: 597-610. http://dx.doi.org/10.1038/ $\underline{\operatorname{nrg} 2843}$

[9] BAEK D, VILLEN J, SHIN C, CAMARGO FD, GYGI SP, BARTEL DP. The impact of microRNAs on protein output. Nature 2008; 455: 64-71. http://dx.doi.org/10.1038/nature 07242

[10] LIU C, TANG DG. MicroRNA regulation of cancer stem cells. Cancer Res 2011; 71: 5950-5954. http://dx.doi. org/10.1158/0008-5472.CAN-11-1035

[11] LI Z, YANG CS, NAKASHIMA K, RANA TM. Small RNAmediated regulation of iPS cell generation. EMBO J 2011; 30: 823-834. http://dx.doi.org/10.1038/emboj.2011.2

[12] TAY Y, ZHANG J, THOMSON AM, LIM B, RIGOUTSOS I. MicroRNAs to Nanog, Oct 4 and Sox 2 coding regions modulate embryonic stem cell differentiation. Nature 2008; 455: 1124-1128. http://dx.doi.org/10.1038/nature07299

[13] FIUME R, FAENZA I, MATTEUCCI A, ASTOLFI A, VITALE M, MARTELLI AM, COCCO L. Nuclear Phospholipase C $\beta 1$ (PLC $\beta 1$ ) Affects CD24 Expression in Murine Erythroleukemia Cells. Journal of Biological Chemistry 2005; 280: 24221-24226. http://dx.doi.org/10.1074/jbc. $\underline{\mathrm{M} 411833200}$

[14] PIAZZI M, BLALOCK WL, BAVELLONI A, FAENZA I, RAFFINI M, TAGLIAVINI F, MANZOLI L, COCCO L. PI-PLC $\beta 1 b$ affects Akt activation, cyclin E expression, and caspase cleavage, promoting cell survival in pro-B-lymphoblastic cells exposed to oxidative stress. FASEB J 2015; 29: 1383-94. http://dx.doi.org/10.1096/fj.14-259051 
[15] SUN X, JIAO X, PESTELL TG, FAN C, QIN S, MIRABELLI E, REN H, PESTELL RG. MicroRNAs and cancer stem cells: the sword and the shield. Oncogene 2013; 33: 4967-77. http:// dx.doi.org/10.1038/onc.2013.492

[16] YANG ZF, HO DW, NG MN, LAU CK, YU WC, NGAI P, CHU PW, LAM CT, POON RT, FAN ST. Significance of CD90+ cancer stem cells in human liver cancer. Cancer Cell 2008 13: 153-166. http://dx.doi.org/10.1016/j.ccr.2008.01.013

[17] MA S, CHAN KW, HU L, LEE TK, WO JY, NG IO, ZHENG BJ, GUAN XY. Identification and characterization of tumorigenic liver cancer stem/progenitor cells. Gastroenterology 2007; 132: 2542-2556. http://dx.doi.org/10.1053/j. gastro.2007.04.025

[18] HARAGUCHI N, ISHII H, MIMORI K, TANAKA F, OHKUMA M, KIM HM, AKITA H, TAKIUCHI D, HATANO $\mathrm{H}, \mathrm{NAGANO} \mathrm{H}, \mathrm{BARNARD}$ GF, DOKI Y, MORI M. CD13 is a therapeutic target in human liver cancer stem cells. J Clin Invest 2010; 120: 3326-3339. http://dx.doi.org/10.1172/ $\underline{\mathrm{CCI} 42550}$

[19] LEE TK, CASTILHO A, CHEUNG VC, TANG KH, MA S, NG IO. CD24(+) liver tumor-initiating cells drive self-renewal and tumor initiation through STAT3-mediated NANOG regulation. Cell Stem Cell 2011; 9: 50-63. http://dx.doi. org/10.1016/j.stem.2011.06.005
[20] BARTEL DP. MicroRNAs: genomics, biogenesis, mechanism, and function. Cell 2004; 116: 281-297. http://dx.doi. org/10.1016/S0092-8674(04)00045-5

[21] ZIMMERMAN AL, WU S. MicroRNAs, cancer and cancer stem cells. Cancer Lett 2011; 300: 10-19. http://dx.doi. org/10.1016/j.canlet.2010.09.019

[22] RADOJICIC J, ZARAVINOS A, VREKOUSSIS T, KAFOUSI M, SPANDIDOS DA, STATHOPOULOS EN. MicroRNA expression analysis in triple-negative (ER, PR and Her2/neu) breast cancer. Cell Cycle 2011; 10: 507-517. http://dx.doi. org/10.4161/cc.10.3.14754

[23] NAM EJ, LEE M, YIM GW, KIM JH., Kim S, Kim SW, Kim YT. MicroRNA profiling of a CD133(+) spheroid-forming subpopulation of the OVCAR3 human ovarian cancer cell line. BMC Med Genomics 2012; 5: 18. http://dx.doi. org/10.1186/1755-8794-5-18

[24] YANG YR, FOLLO MY, COCCO L, SUH PG. The physiological roles of primary phospholipase C. Adv Biol Regul 2013; 53: 232-241. http://dx.doi.org/10.1016/j.jbior.2013.08.003

[25] FAENZA I, MATTEUCCI A, MANZOLI L, BILLI AM, ALUIGI M, PERUZZI D, VITALE M, CASTORINA S, SUH PG, COCCO L. A role for nuclear phospholipase Cbeta 1 in cell cycle control. J Biol Chem 2000; 275: 30520-30524. http:// dx.doi.org/10.1074/jbc.M004630200 


\title{
Supplementary Information
}

\section{Down-regulation of miR-205 promotes stemness of hepatocellular carcinoma cells by targeting PLC $\beta 1$ and increasing CD24 expression}

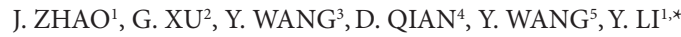

${ }^{1}$ Department of General Surgery, The First Affiliated Hospital of Anhui Medical University, Hefei 230032, China; ${ }^{2}$ Department of Gastroenterology, Drum Tower Hospital Affiliated to Medical School of Nanjing University, Nanjing 210008, China; ${ }^{3}$ Department of Oncology, Wuhu No.2 People's Hospital, 259 Jiuhua Middle Road, Wuhu, 241001, Anhui Province, China; ${ }^{4}$ Department of Oncology, Nanjing Red Cross Hospital,242 Baixia Road, Nanjing 210001, Jiangsu Province, China; ${ }^{5}$ Department of Respiratory Medicine, Drum Tower Hospital Affiliated to Medical School of Nanjing University, Nanjing 210008, China

*Correspondence: yongxiangli_1@hotmail.com 


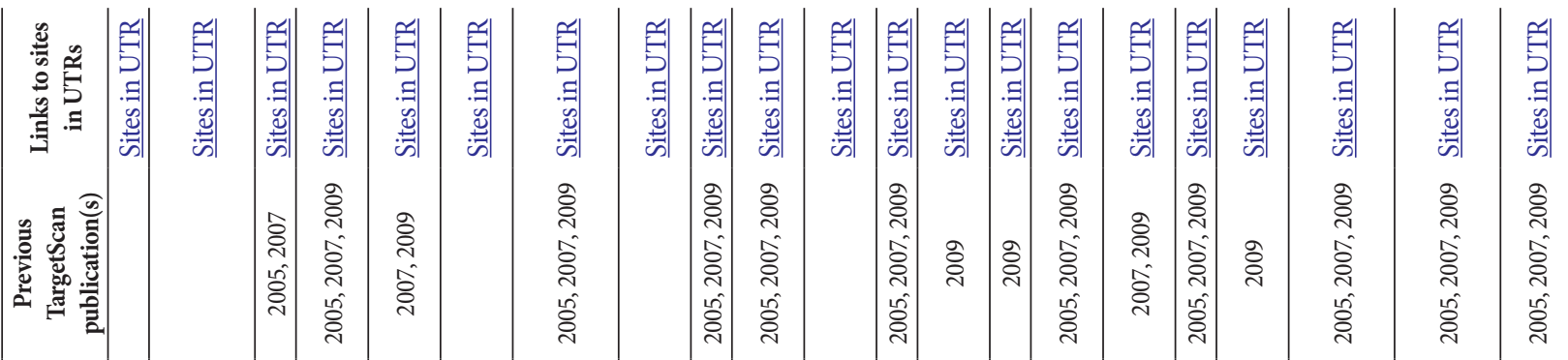

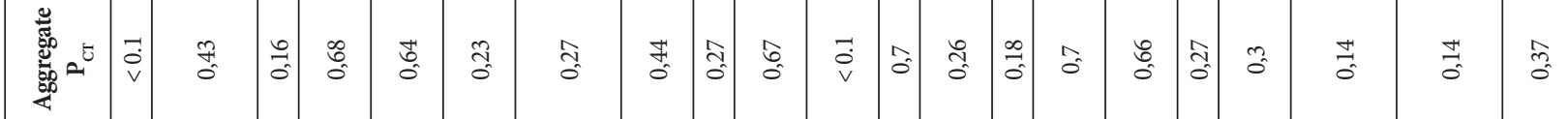

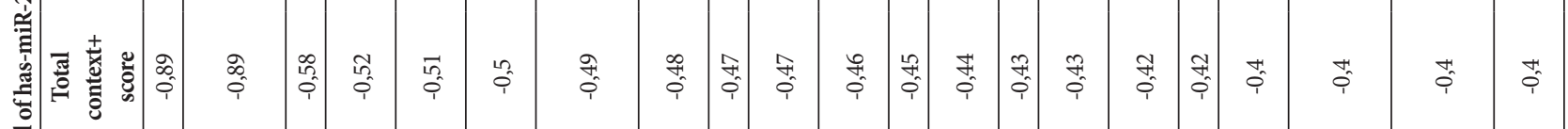

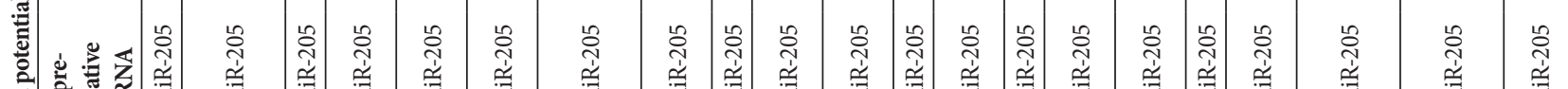

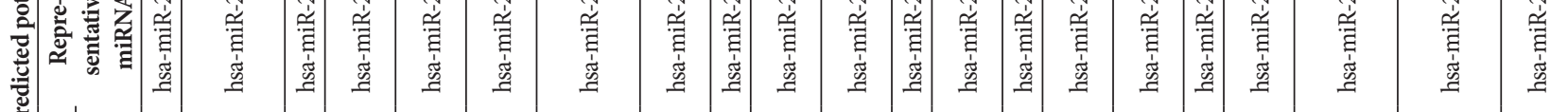

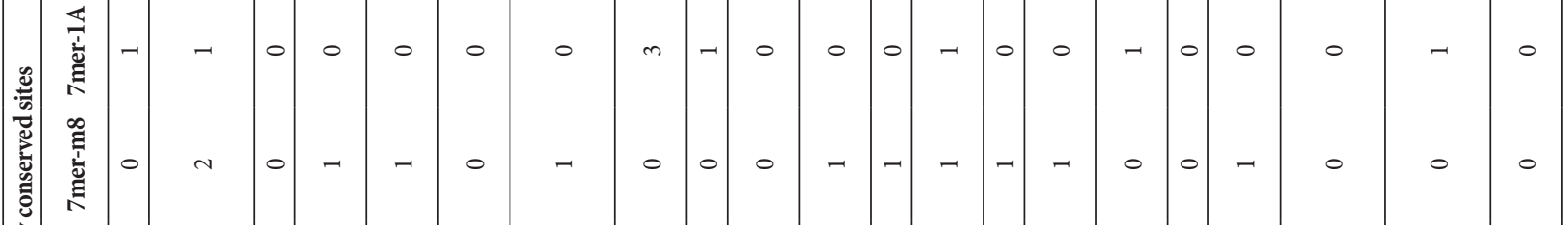

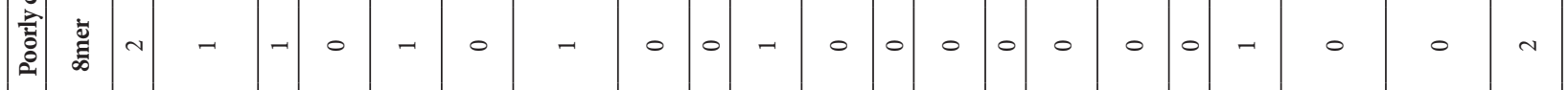

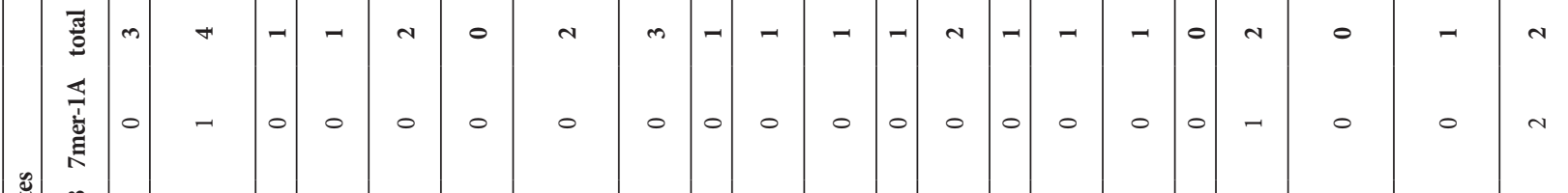

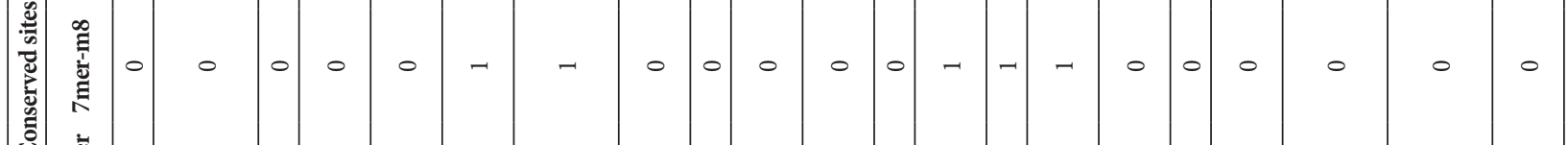

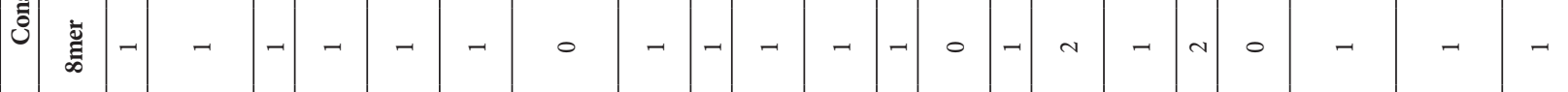

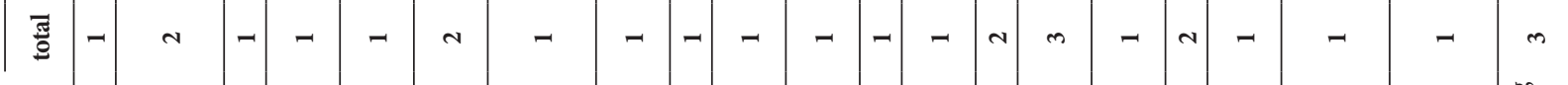

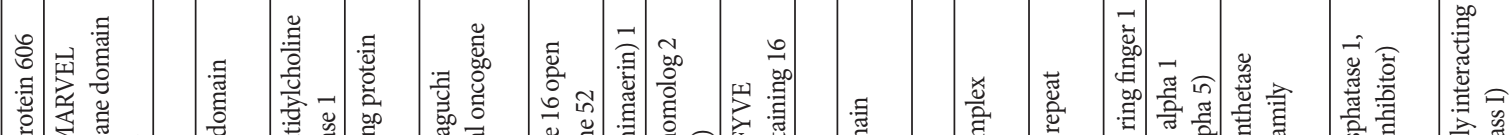

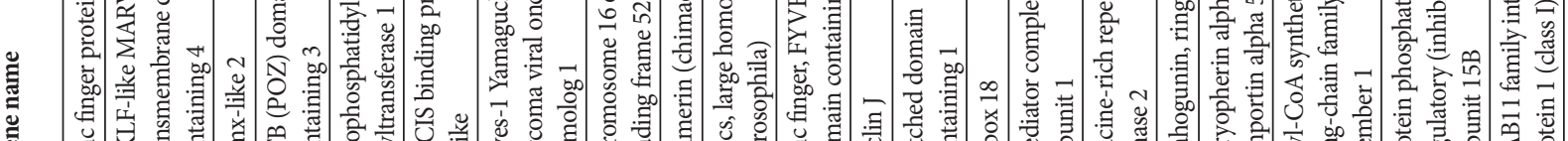

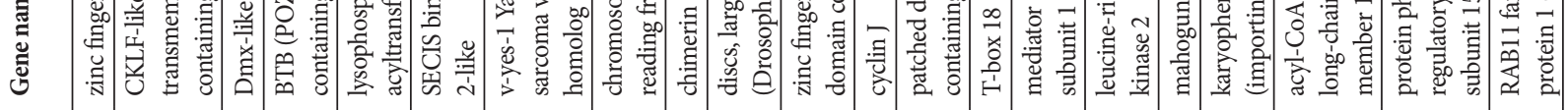

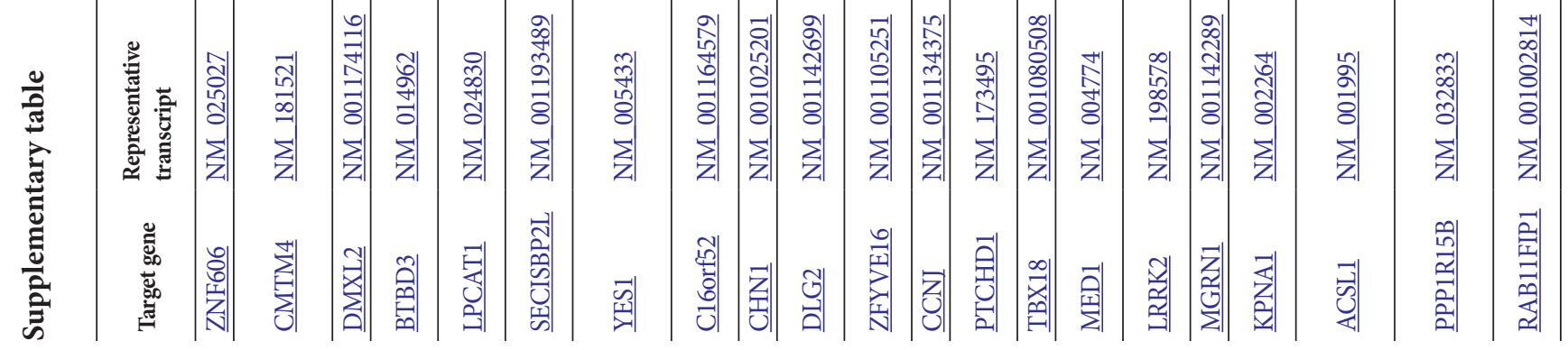




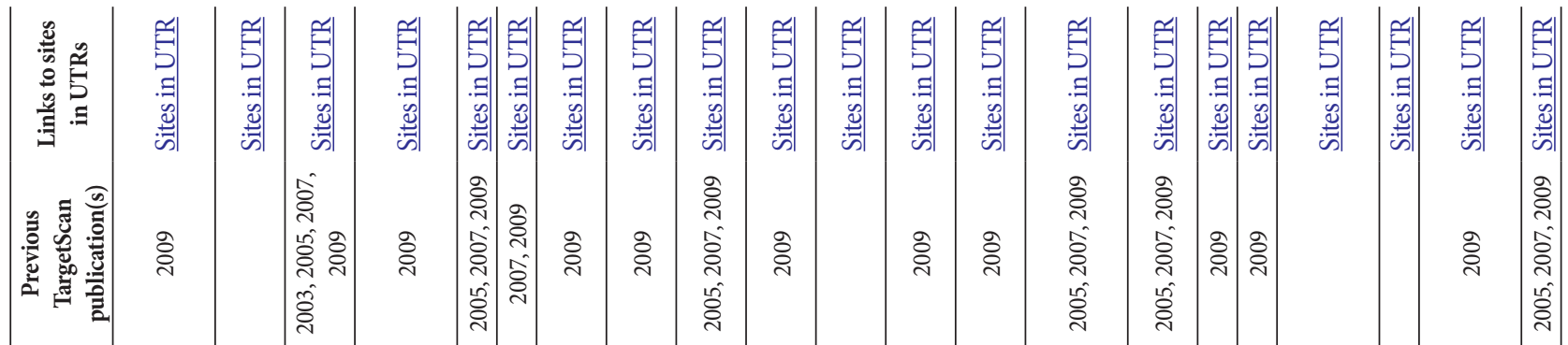

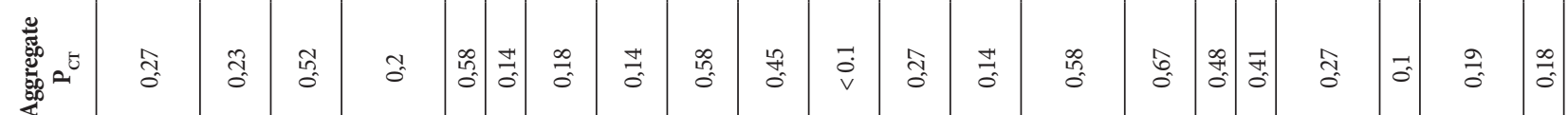
กิ

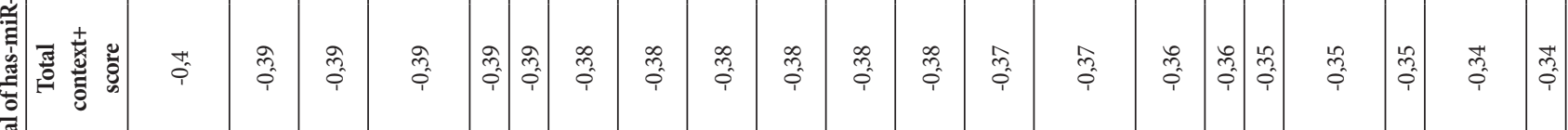

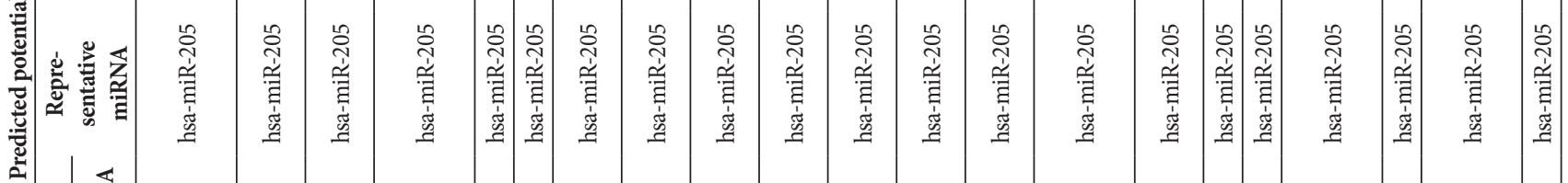

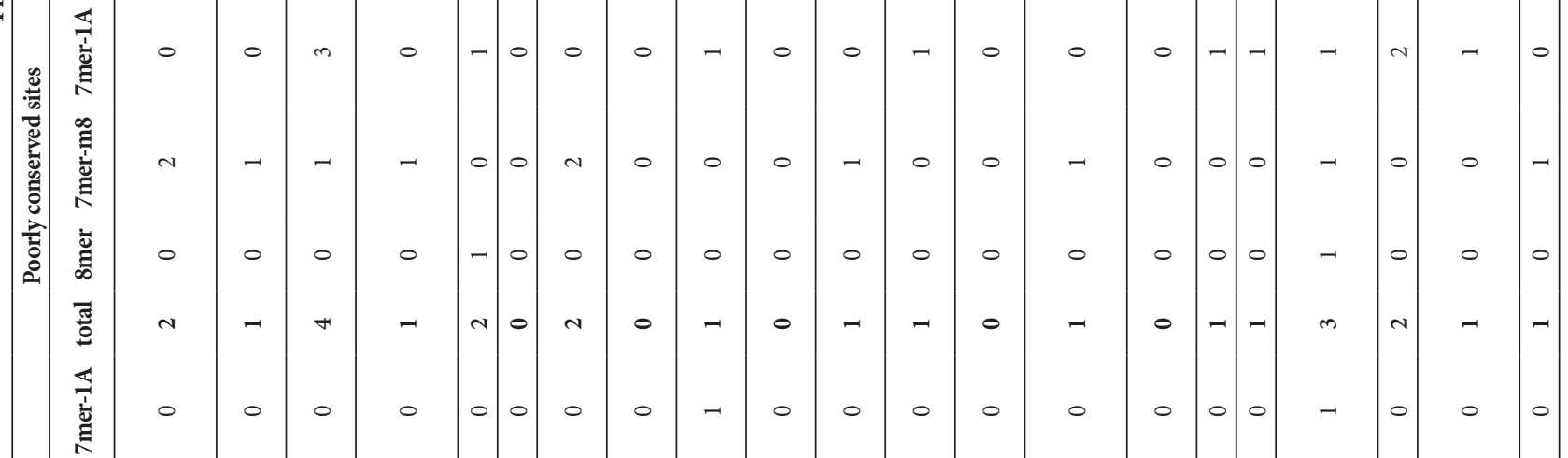

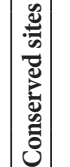

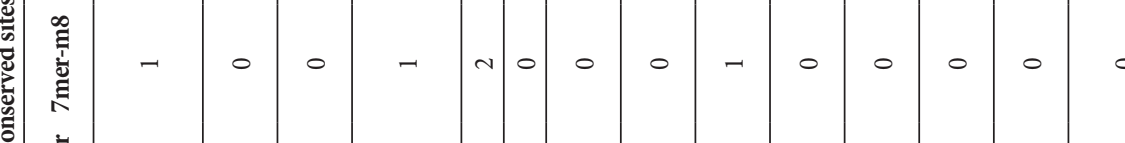

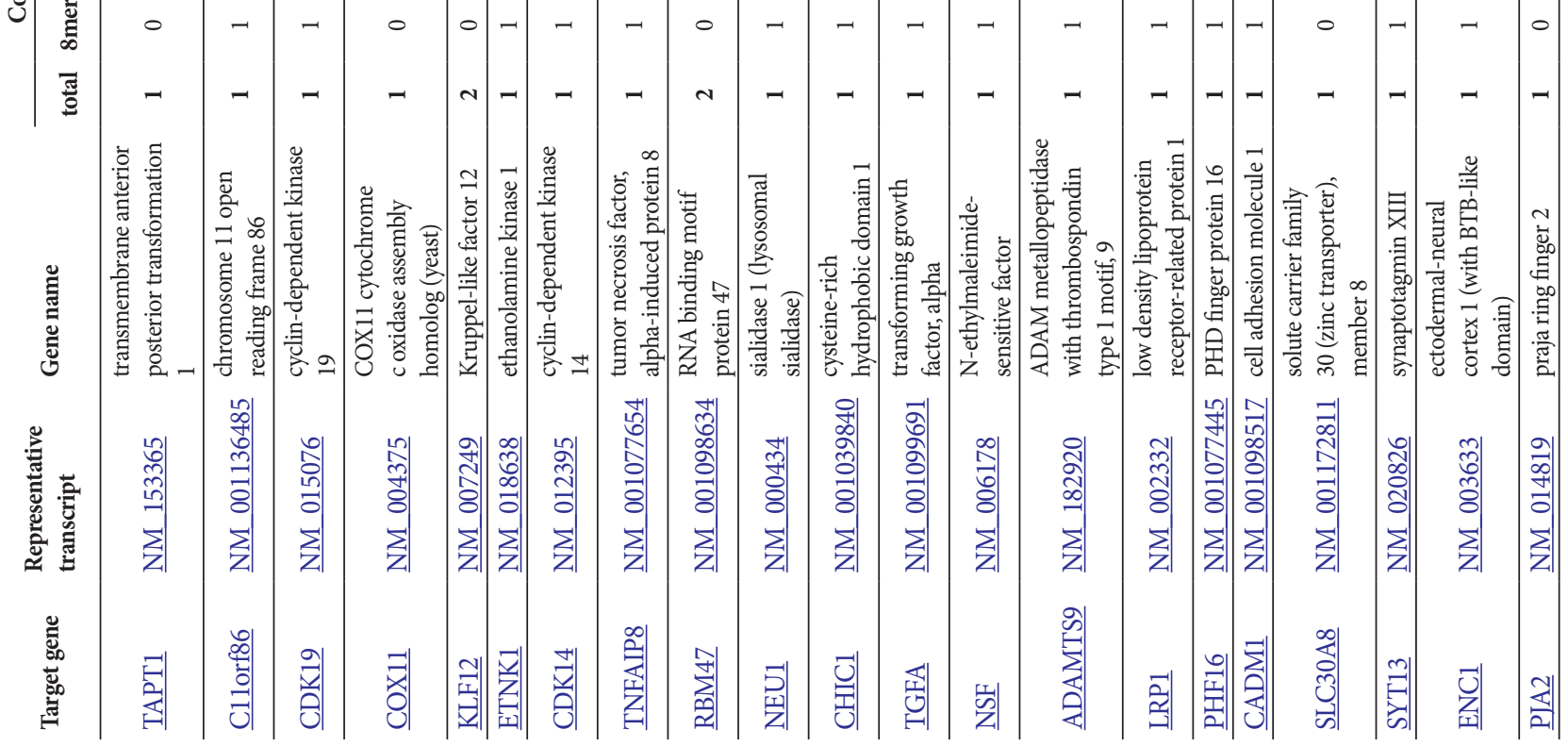




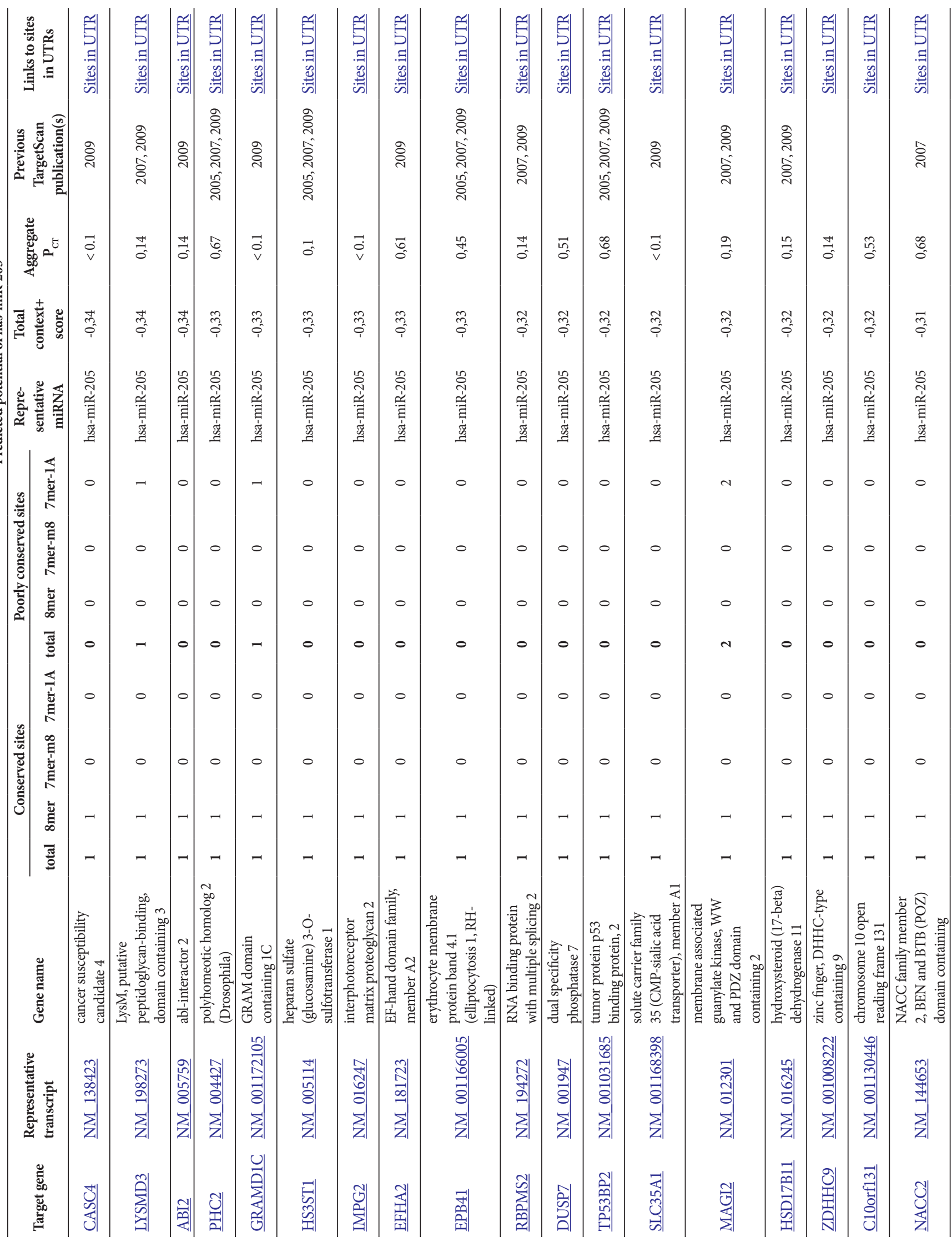




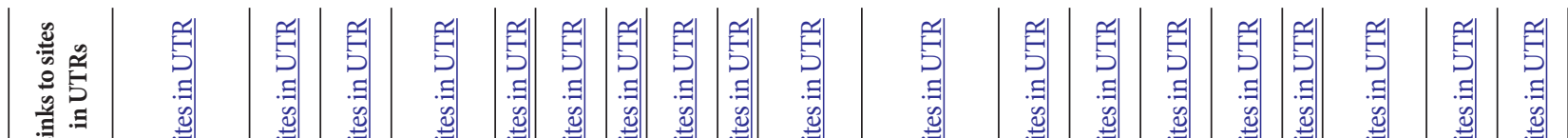

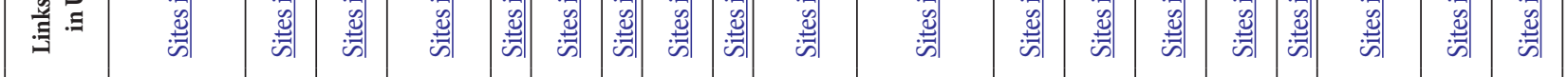

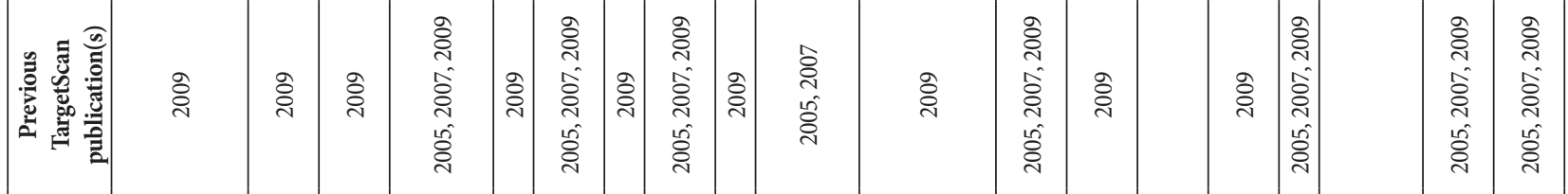

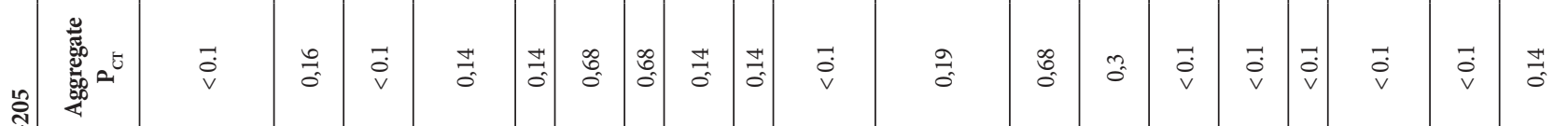

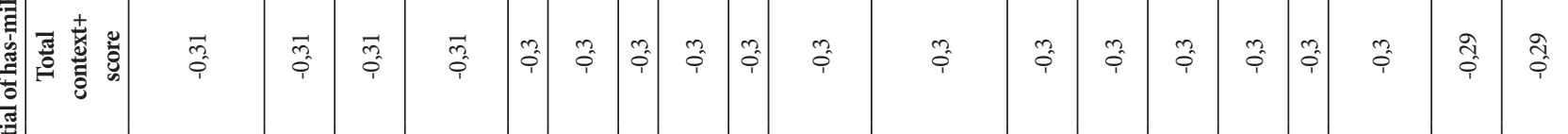
竎

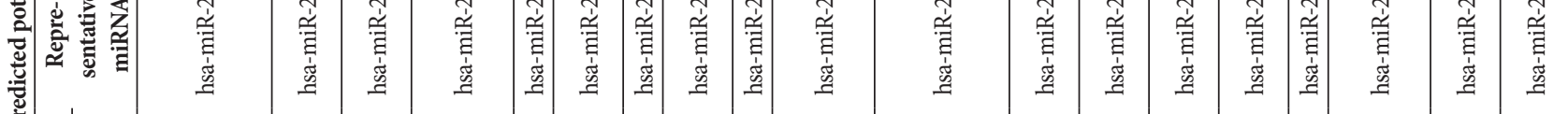

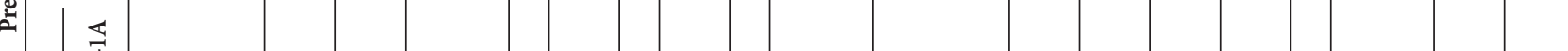

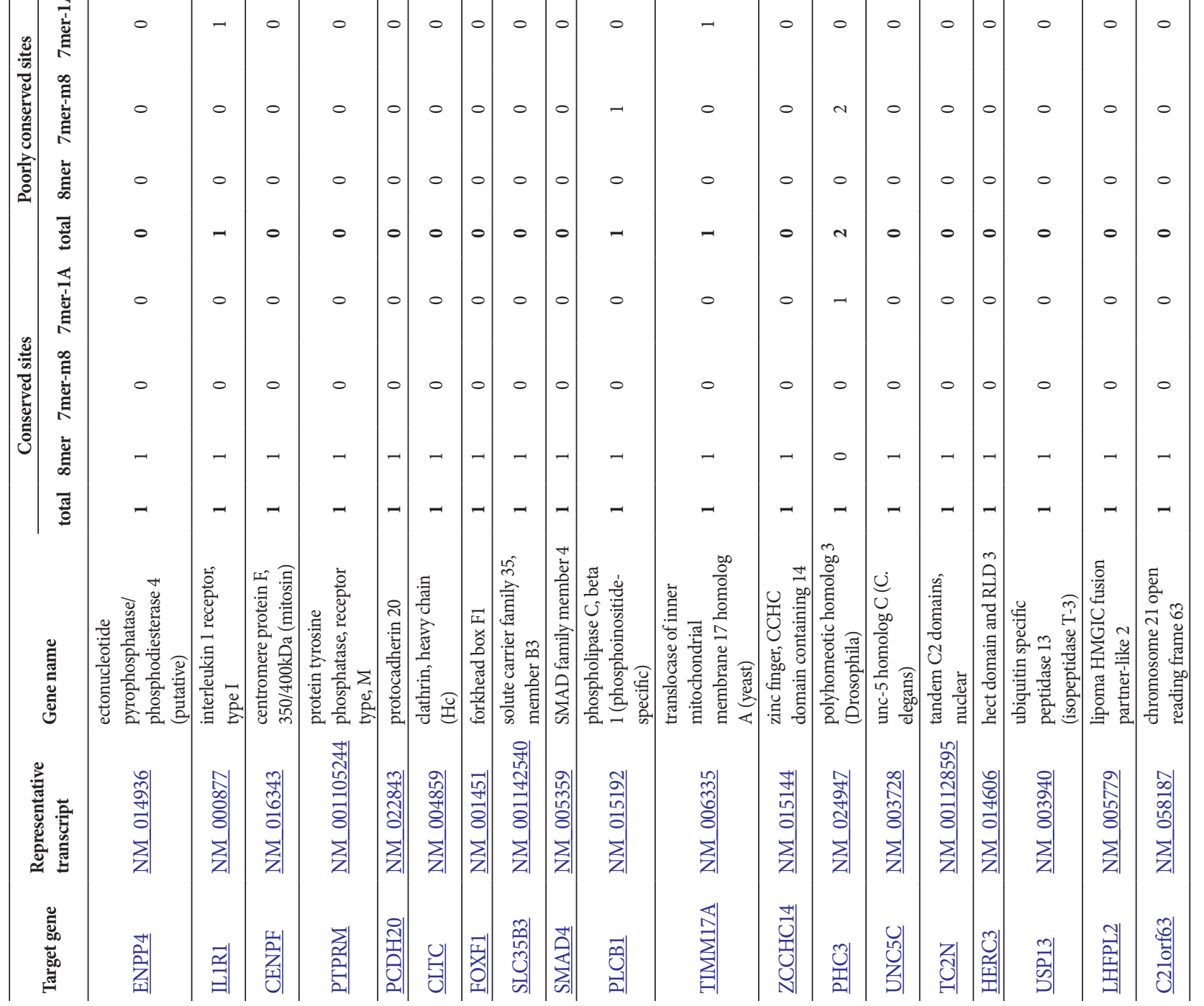




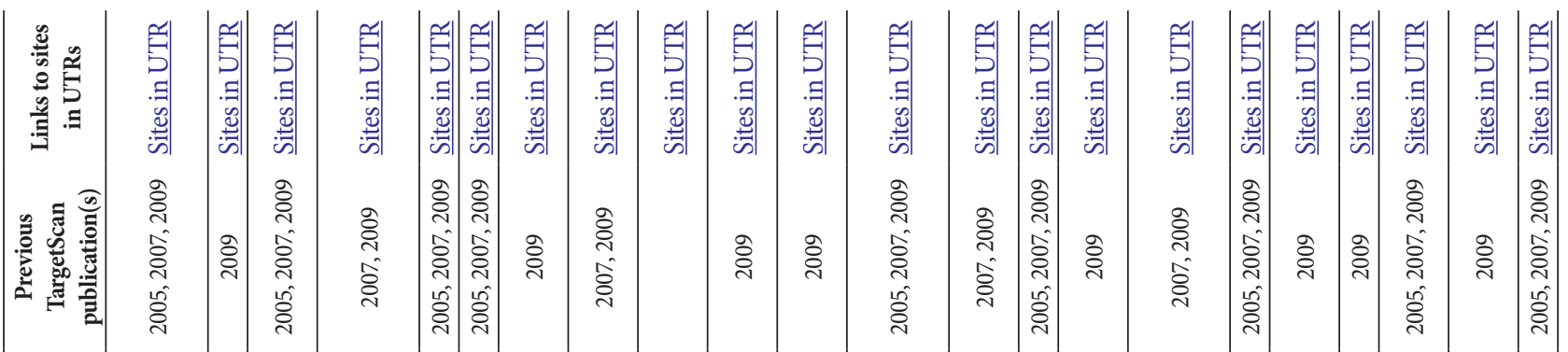

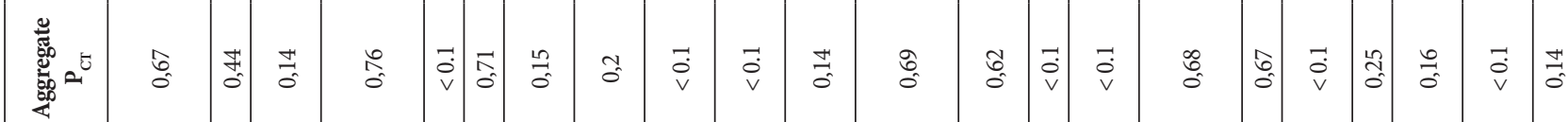
光

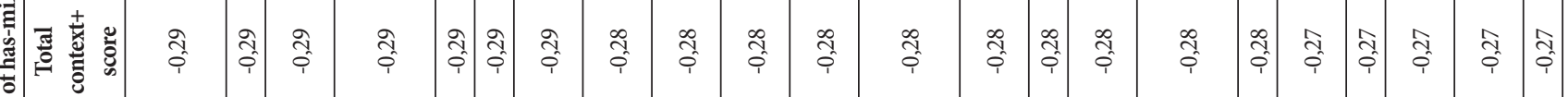

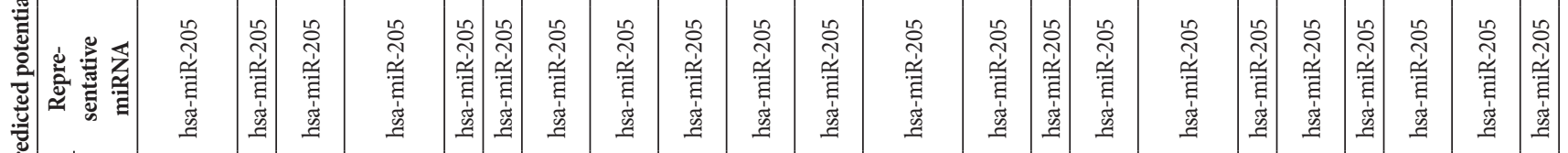
ㄴ.

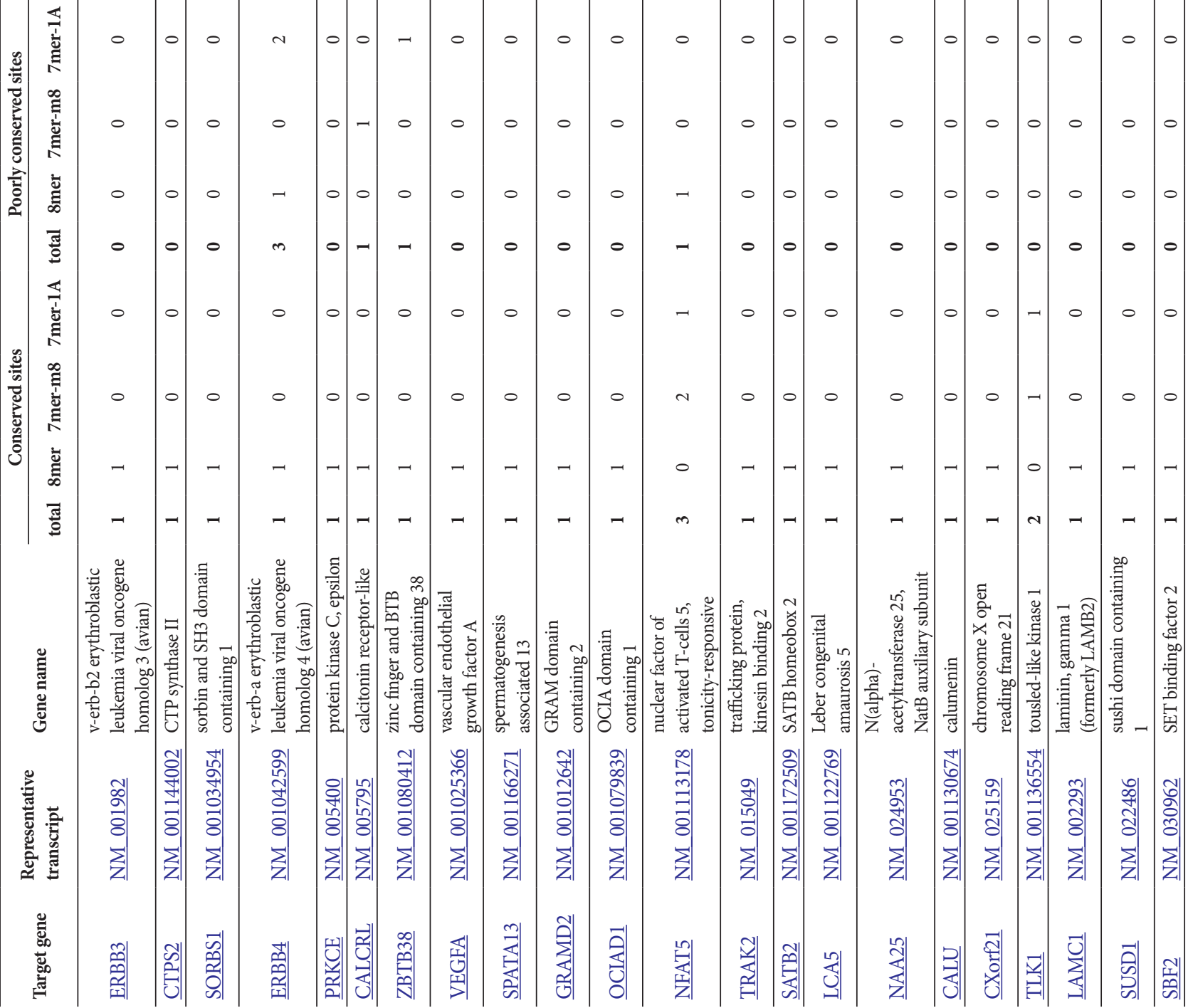




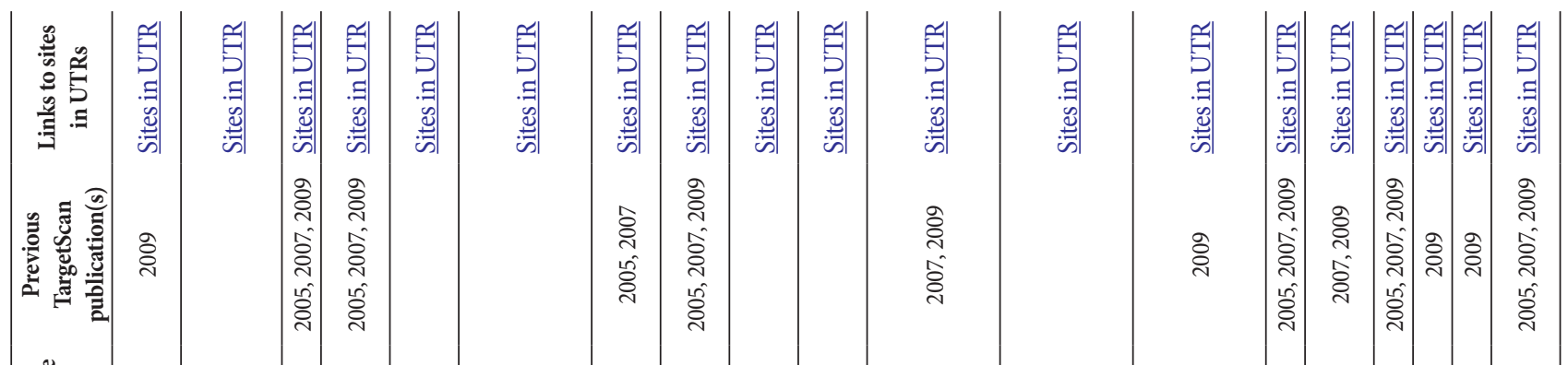

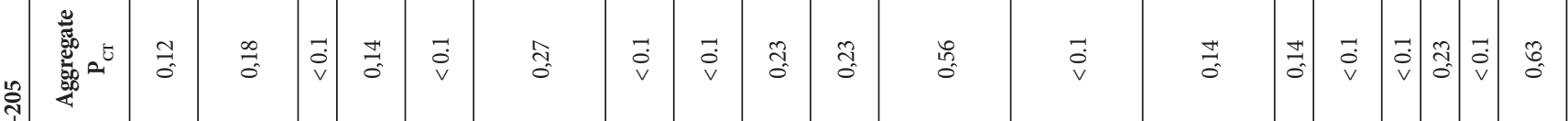

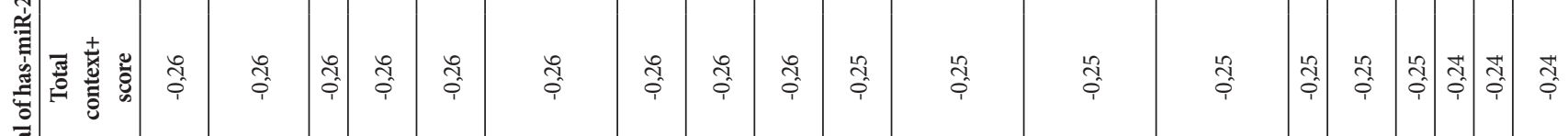

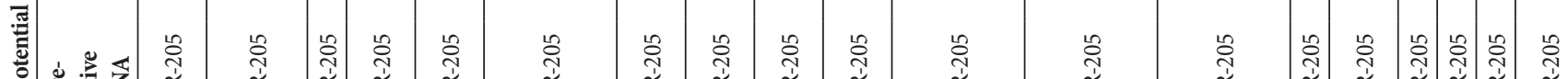

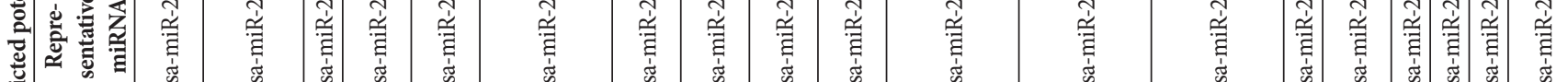

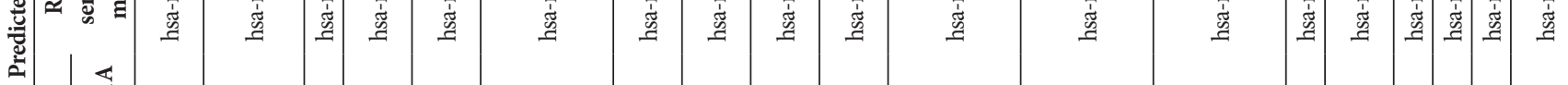

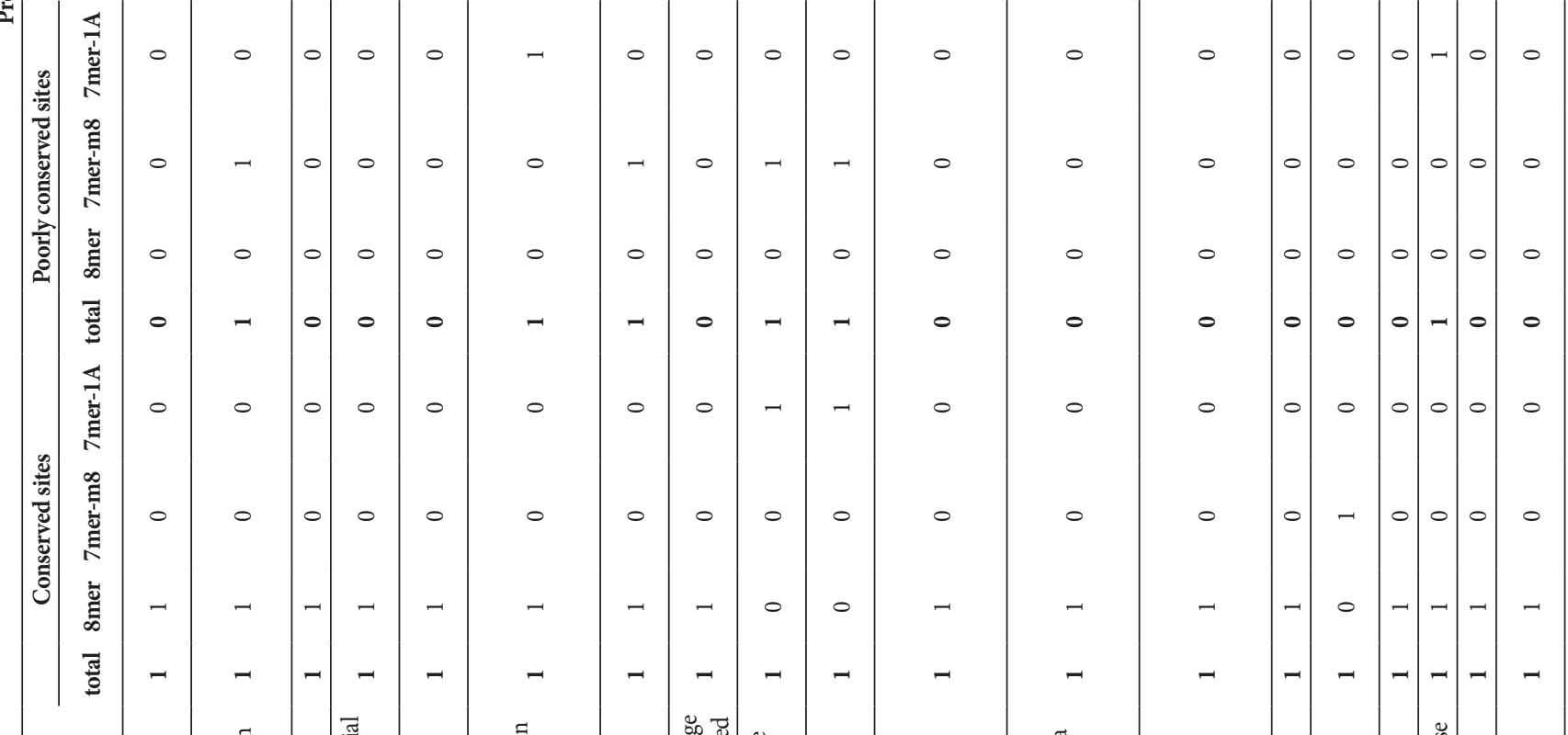

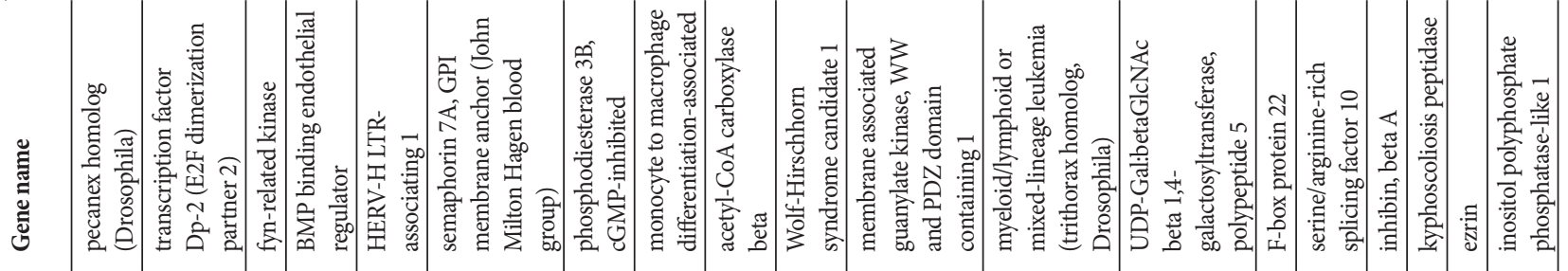

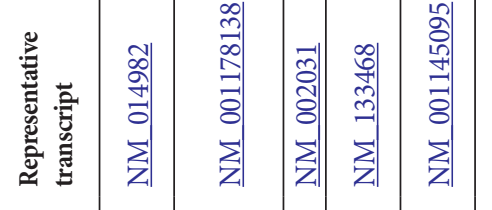

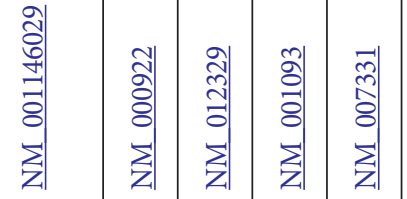
望畜

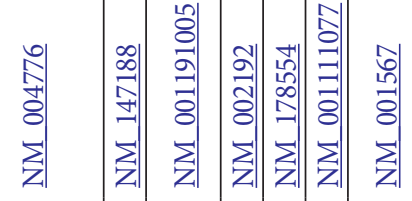

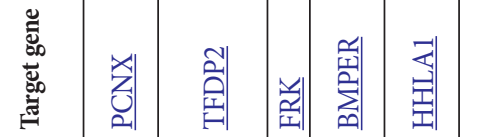

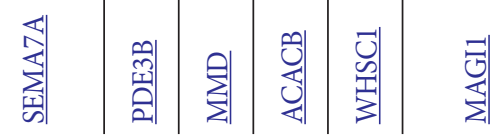
弗

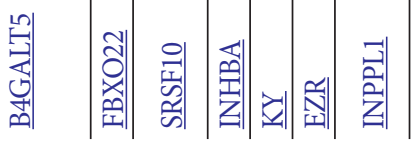




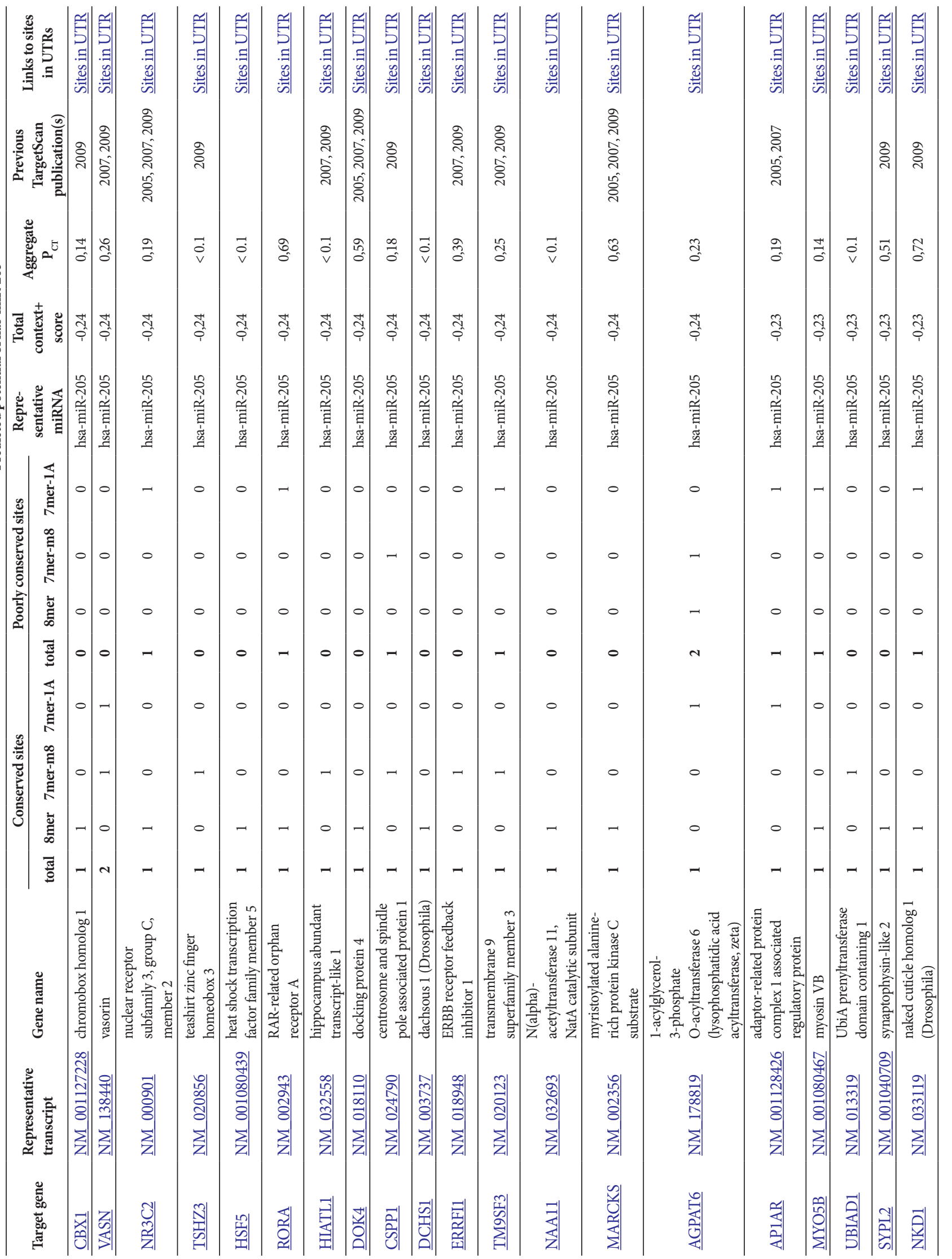




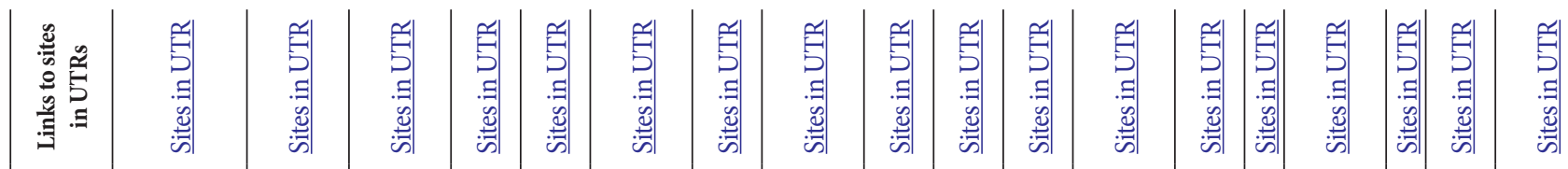

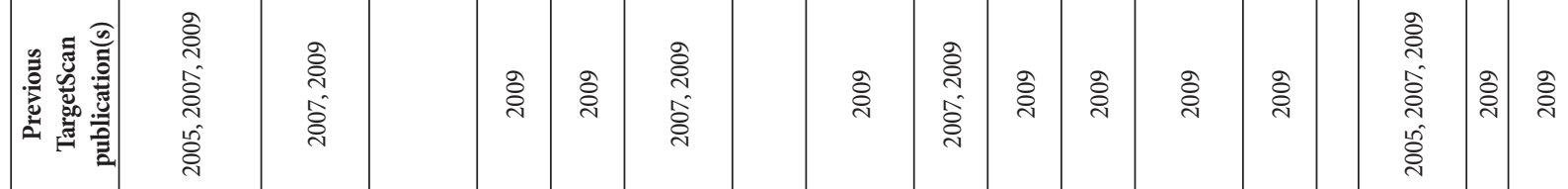

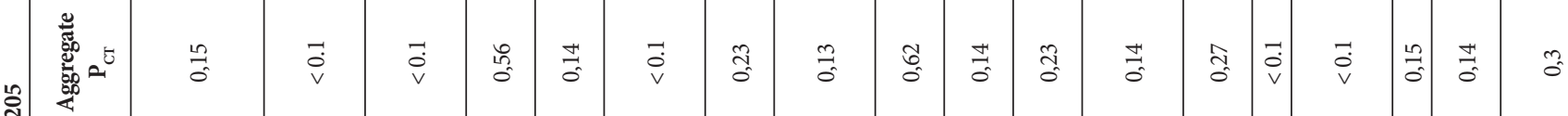

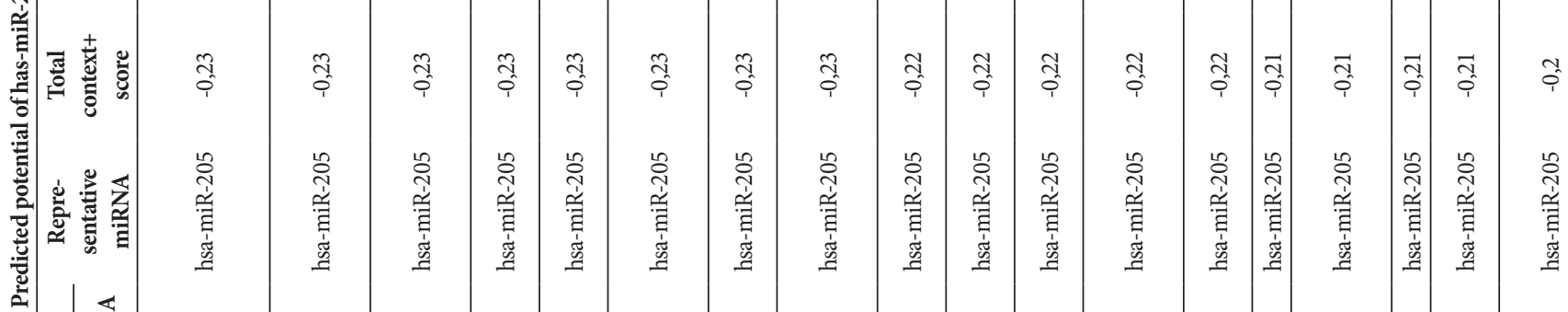

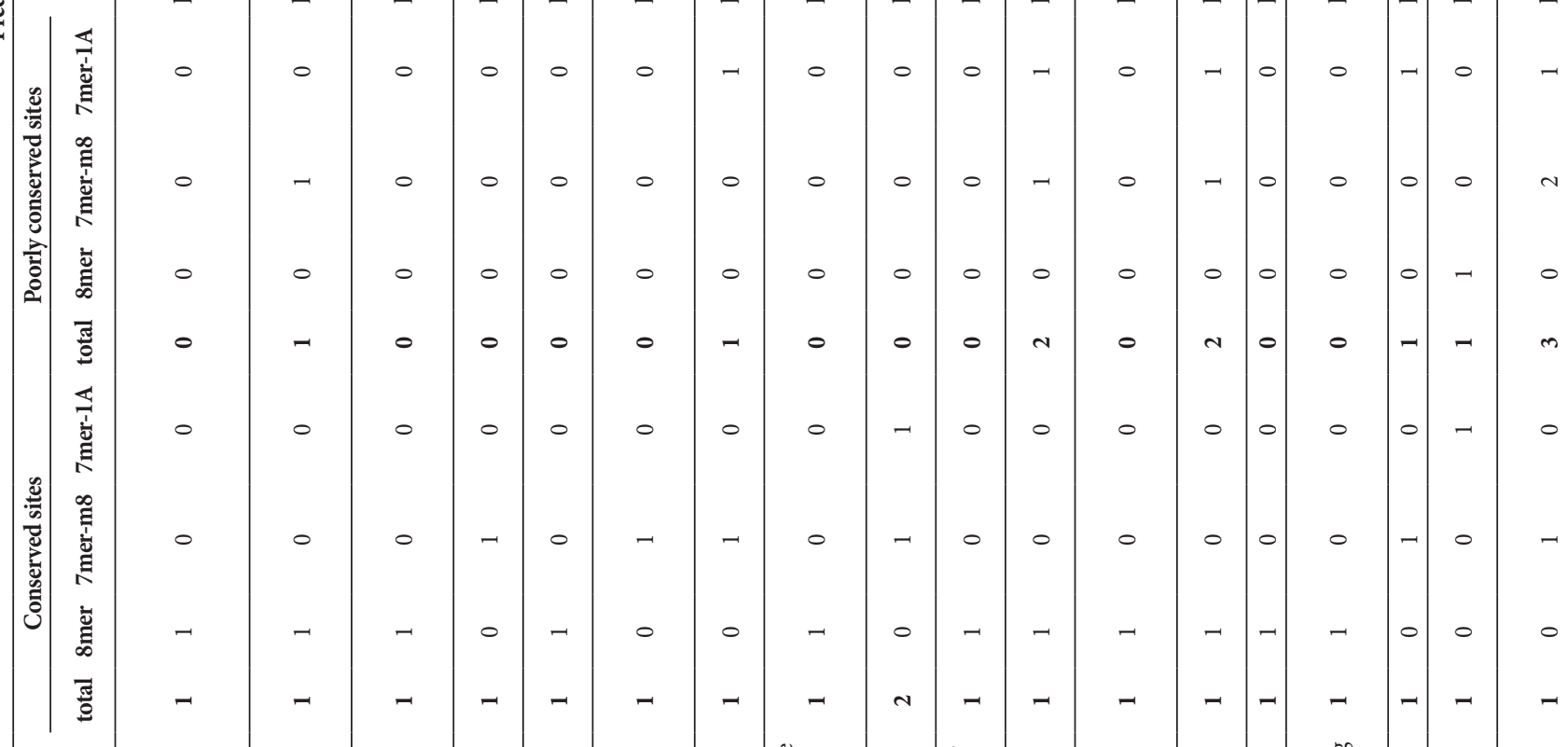

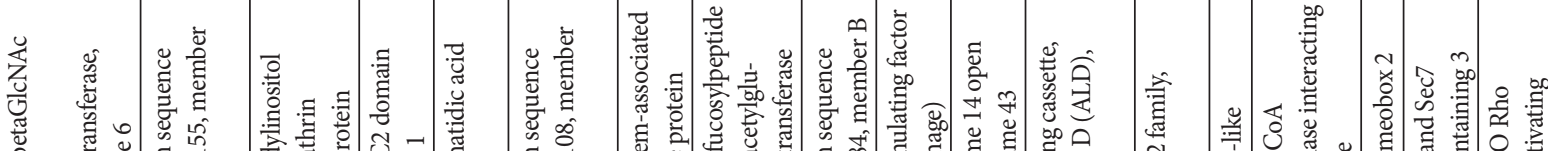

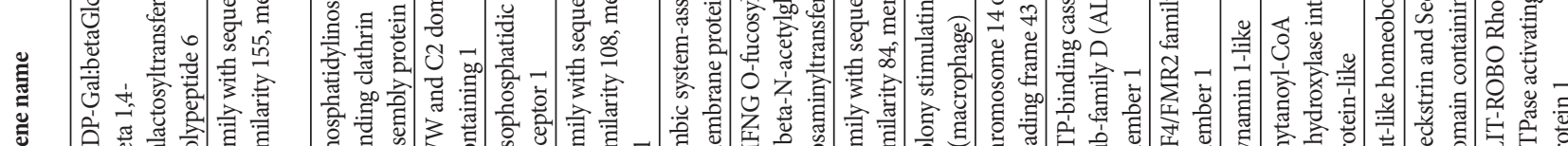

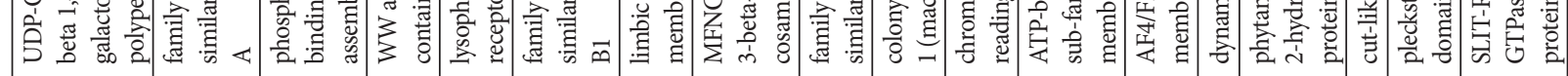

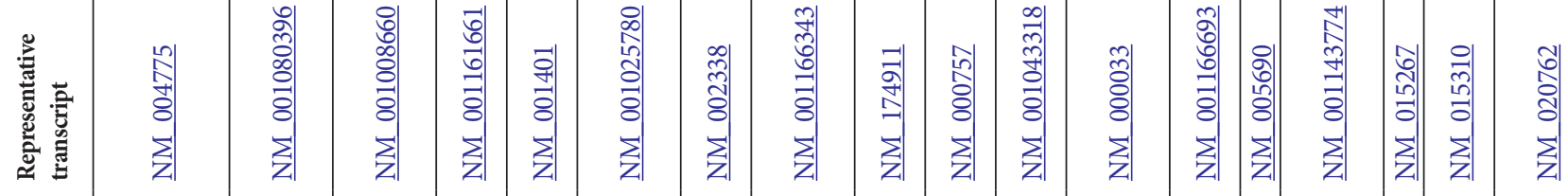

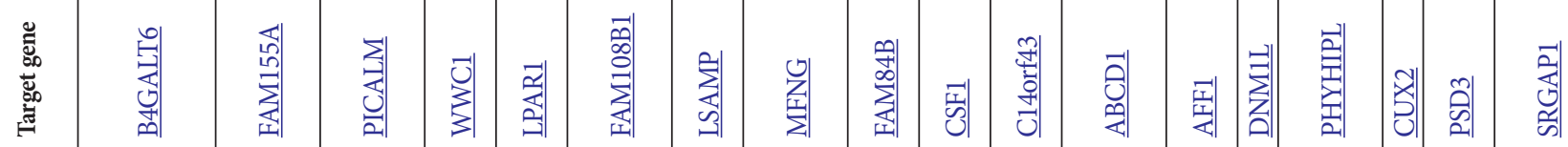




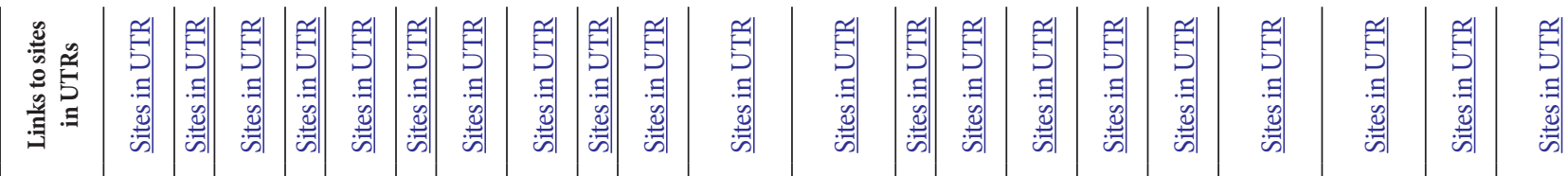

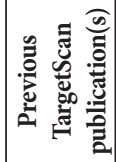
:

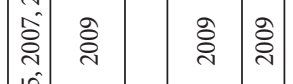

亏

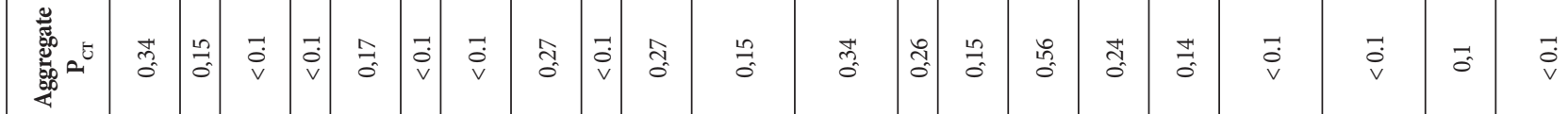

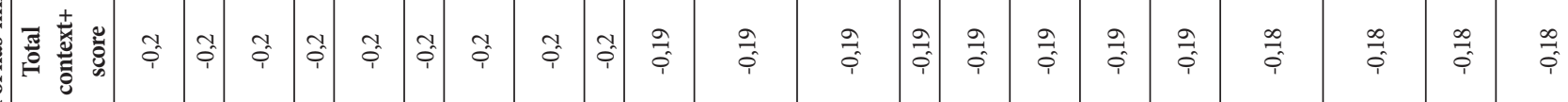

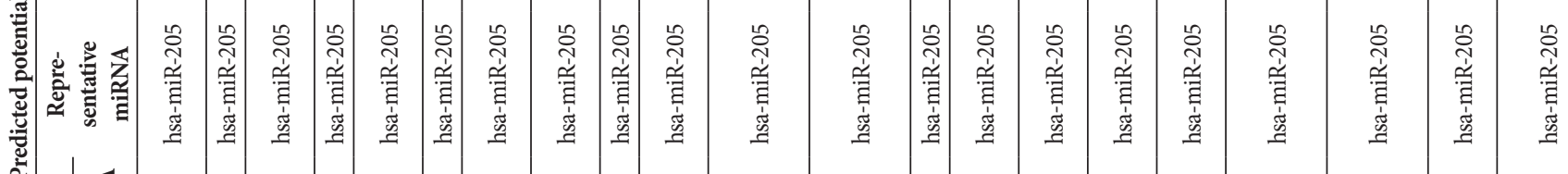
气

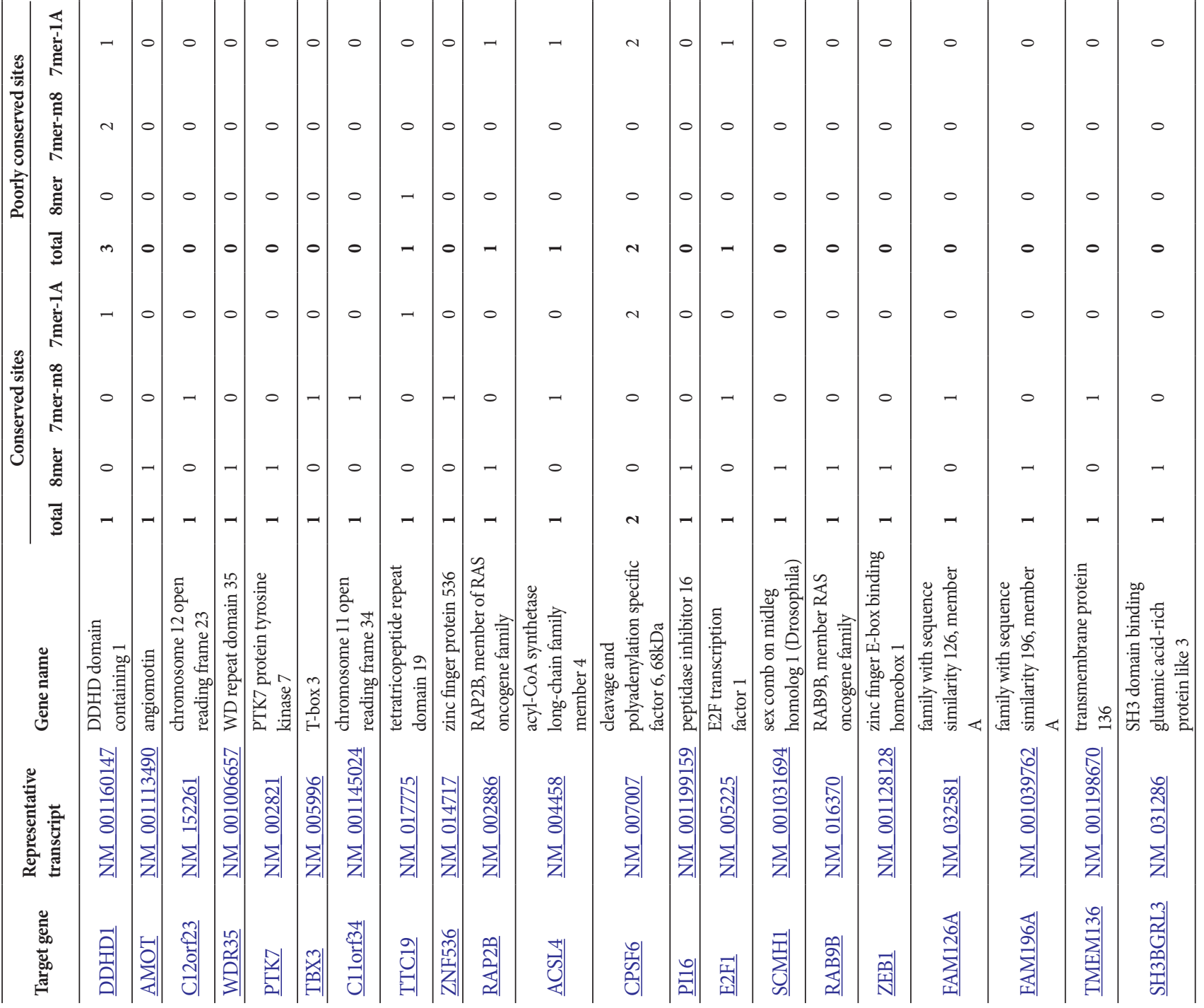




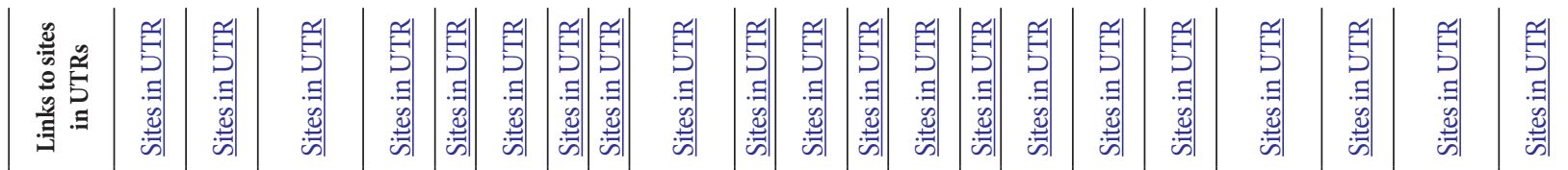

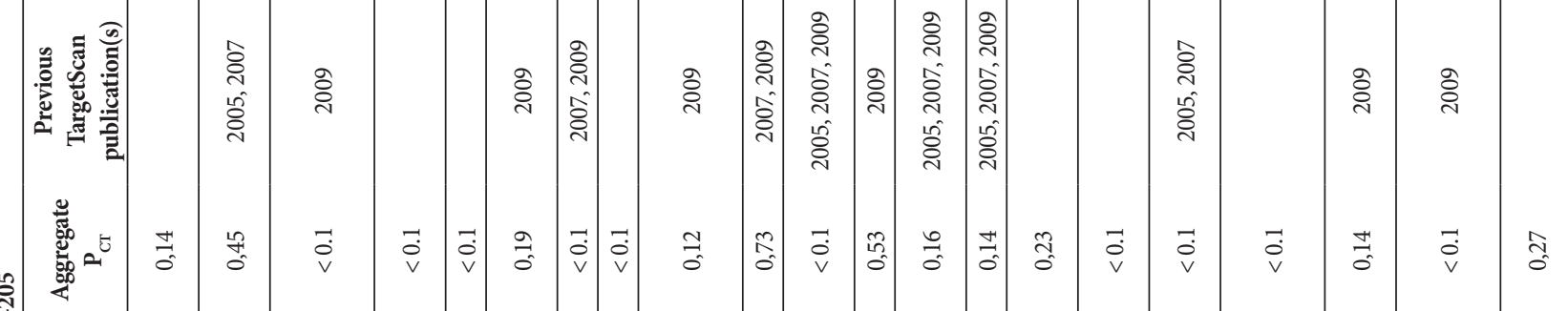

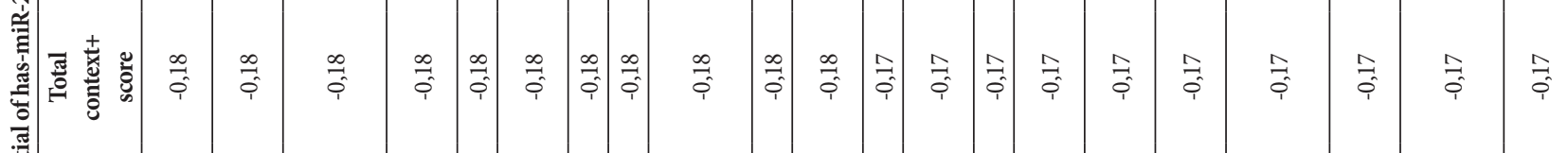

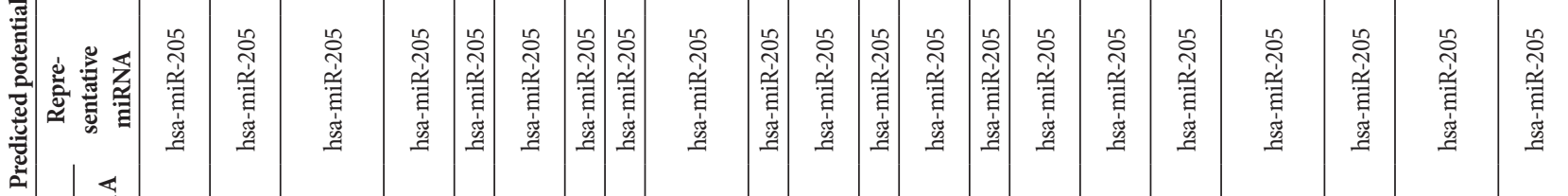

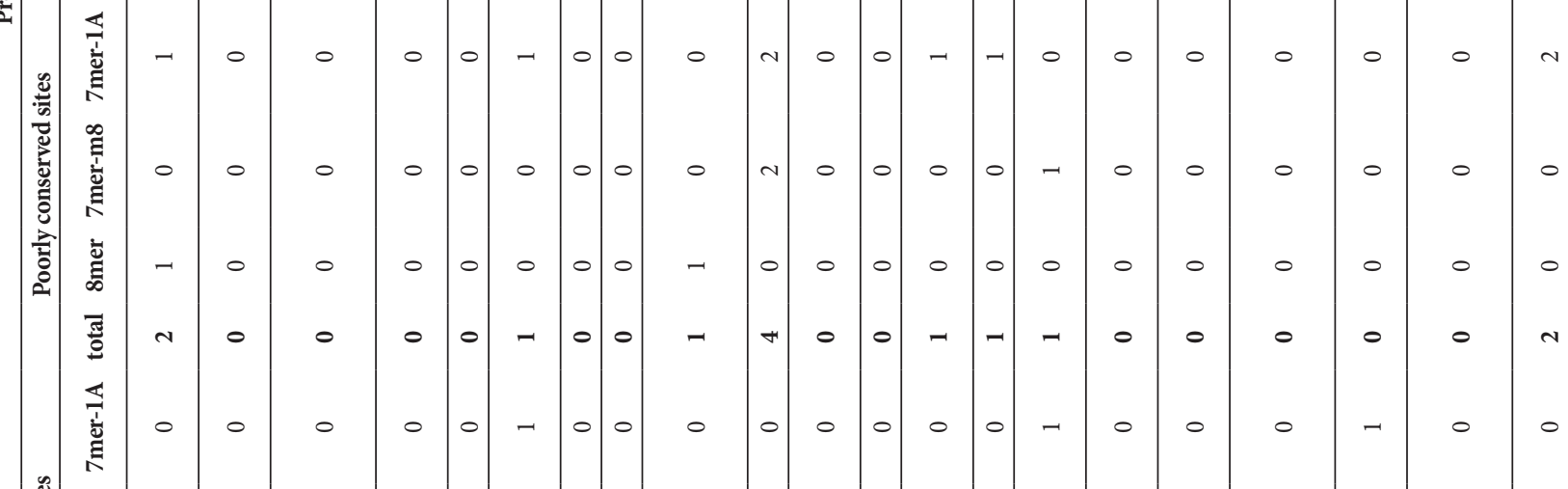

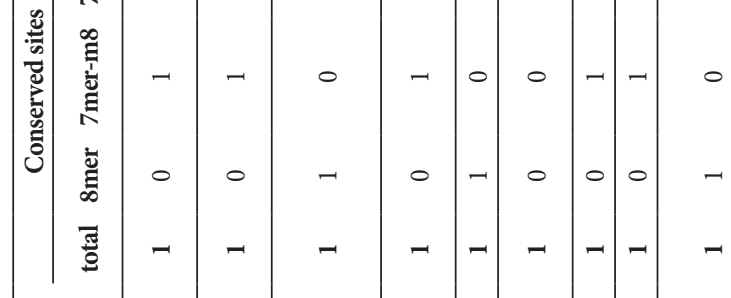

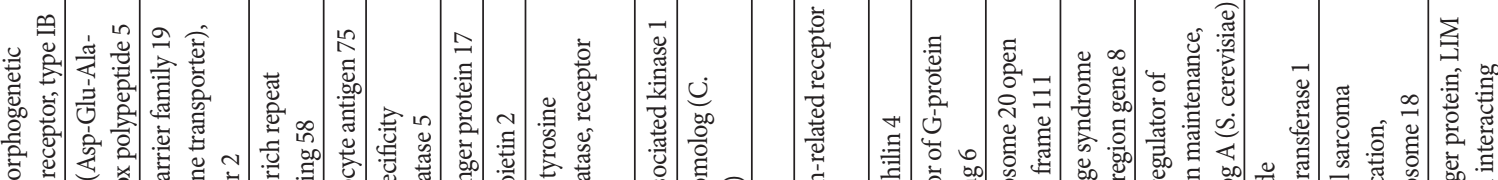

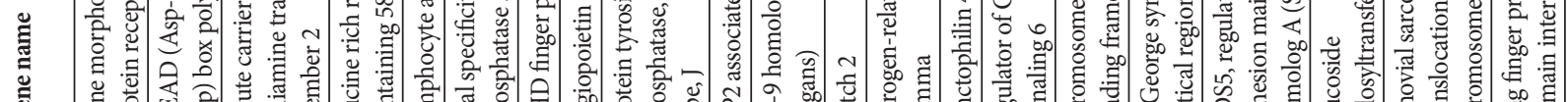

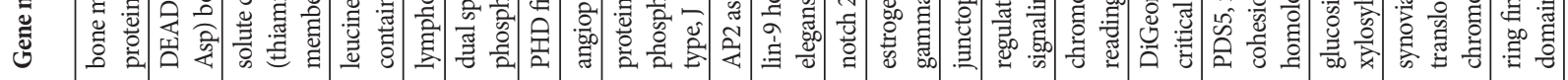

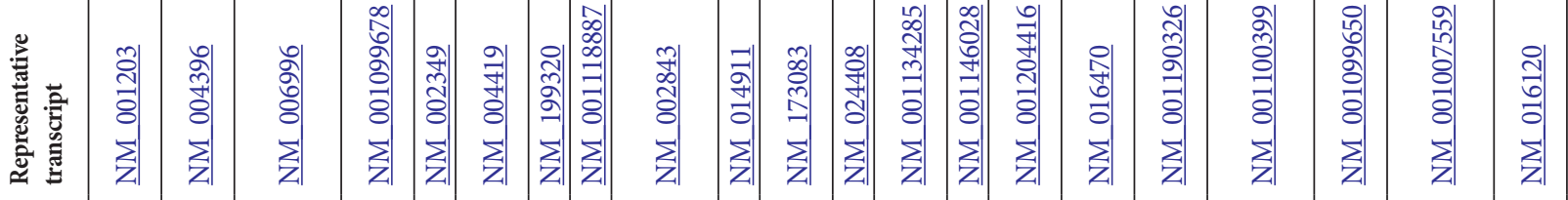

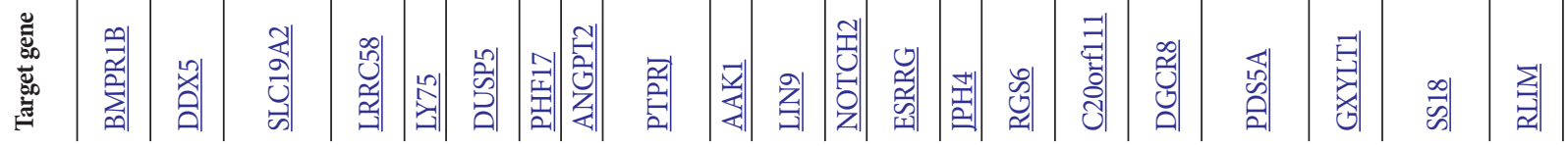




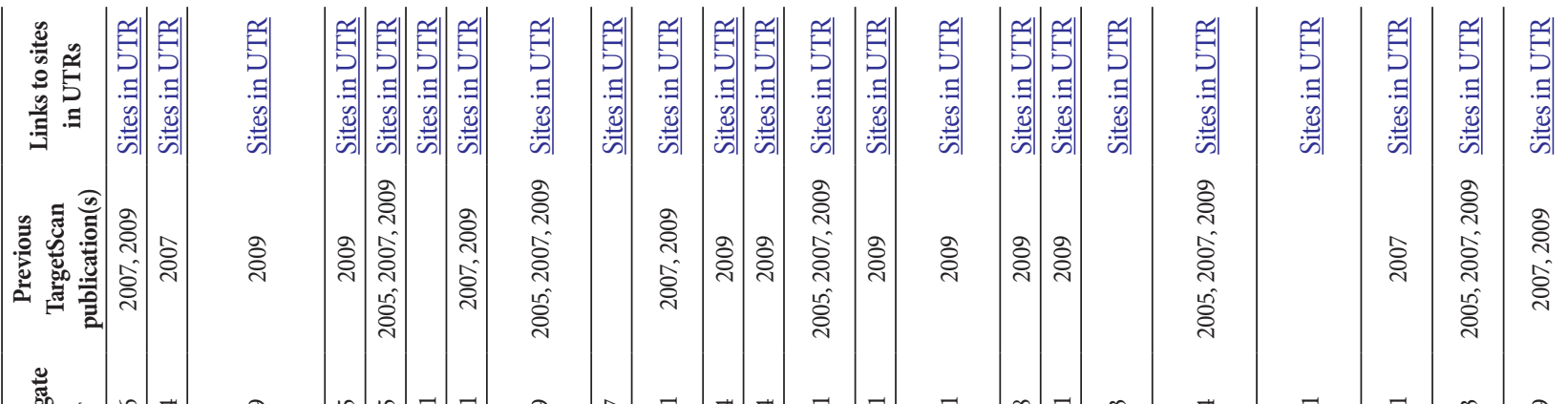
茪

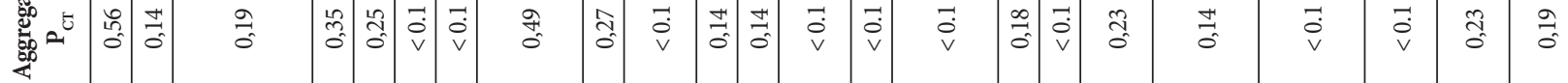

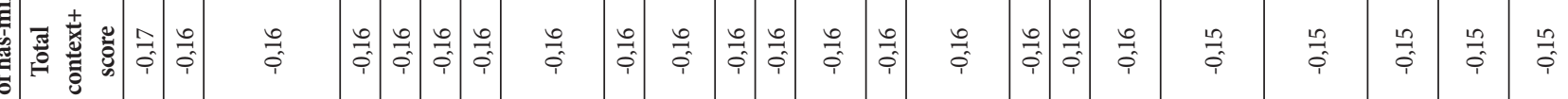

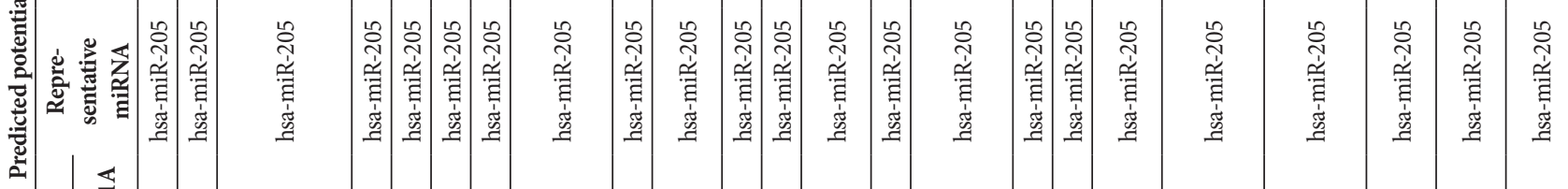

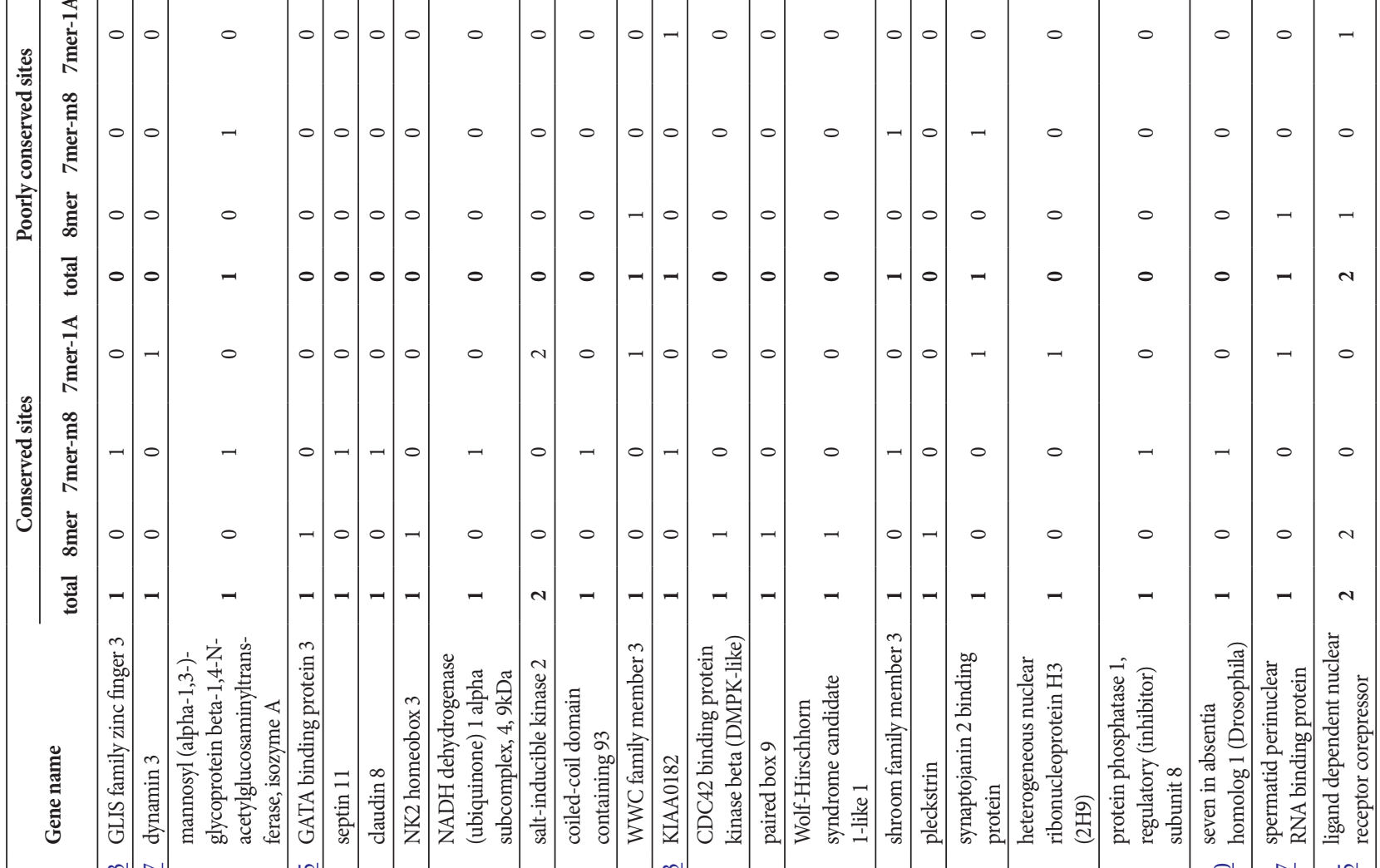

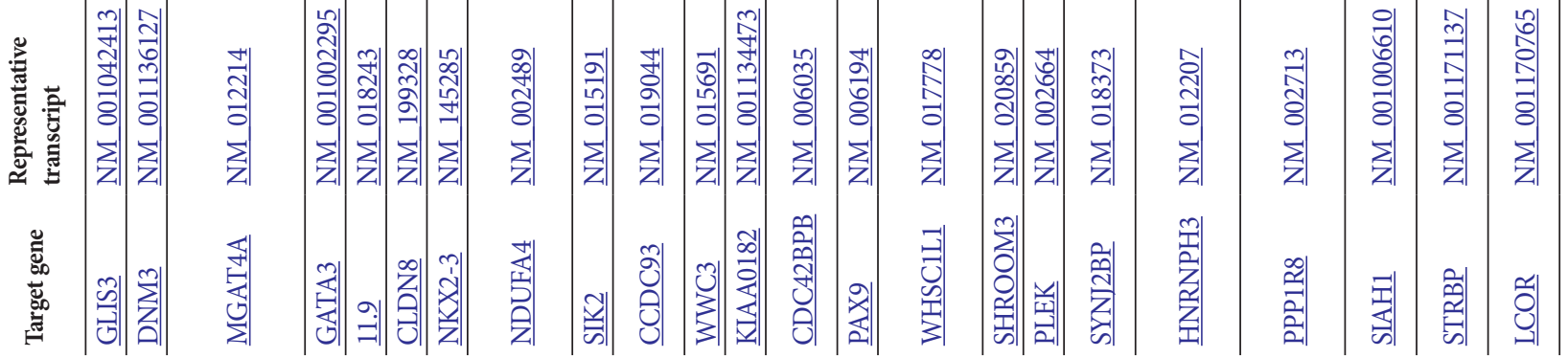




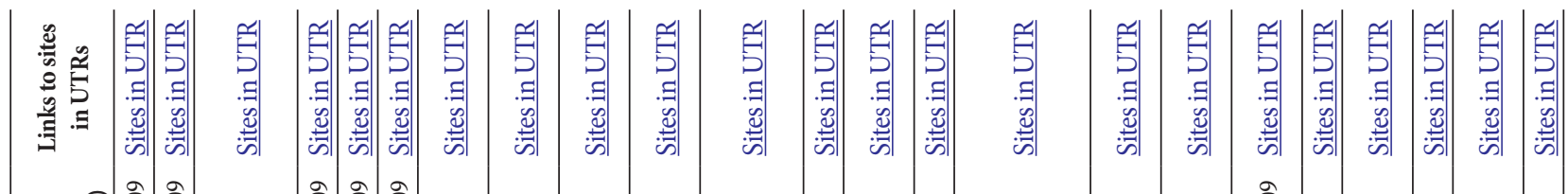

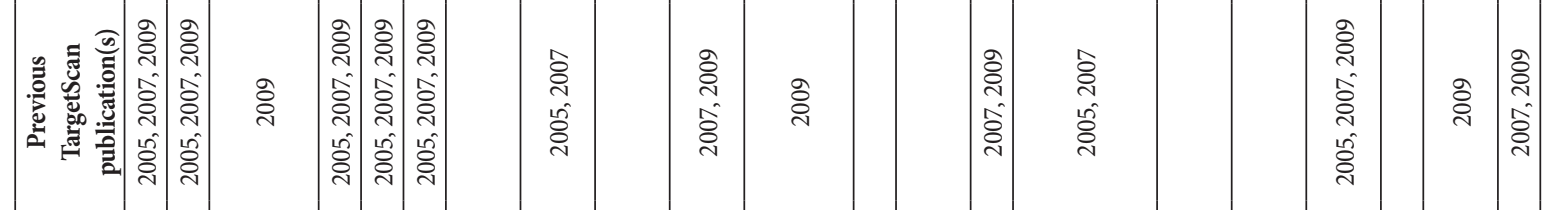

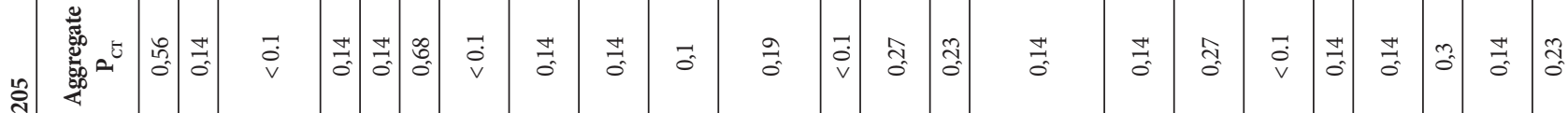

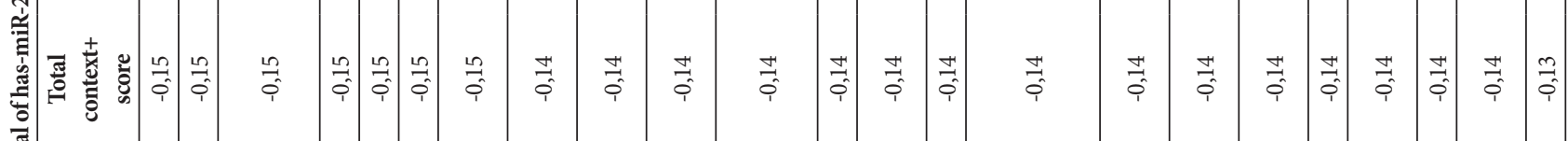

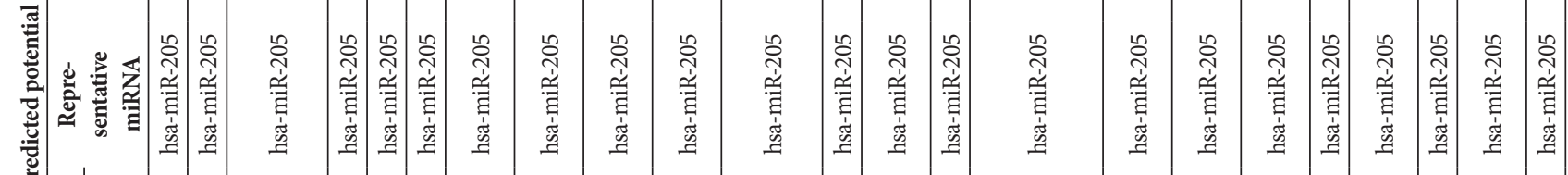

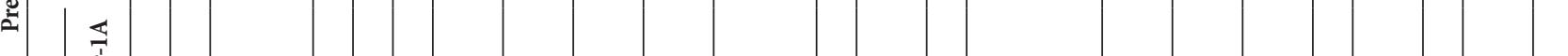
跑

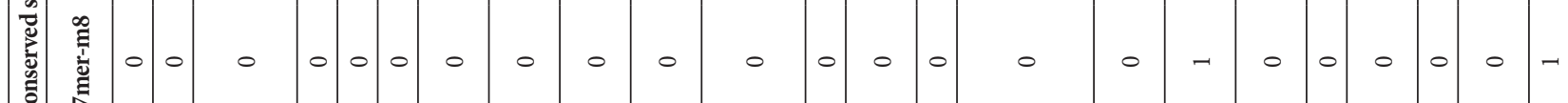
空

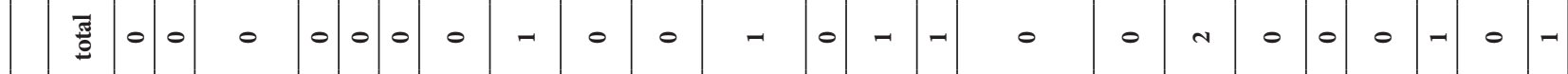

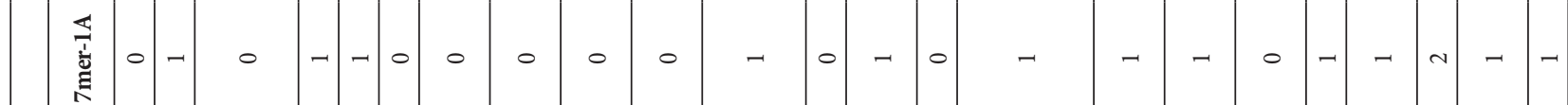
לั.

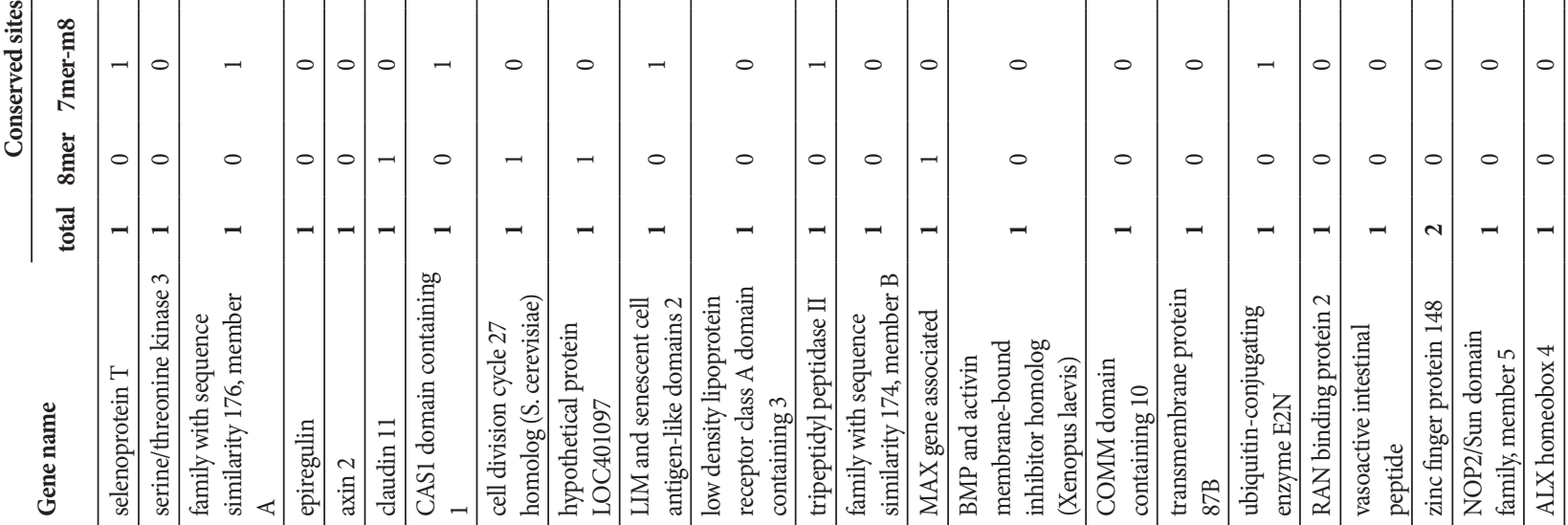

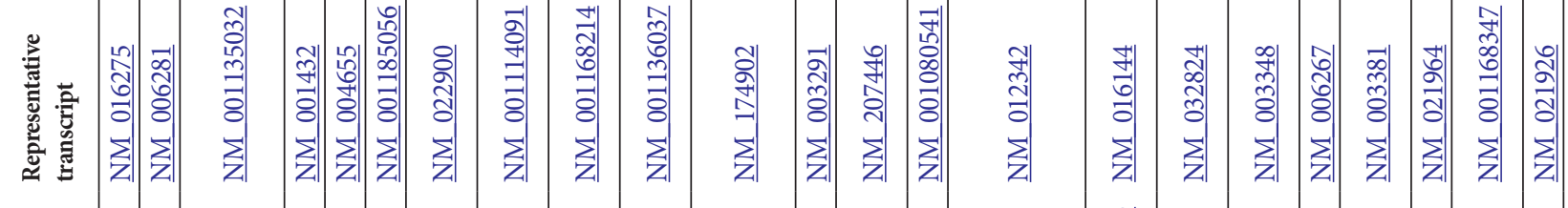

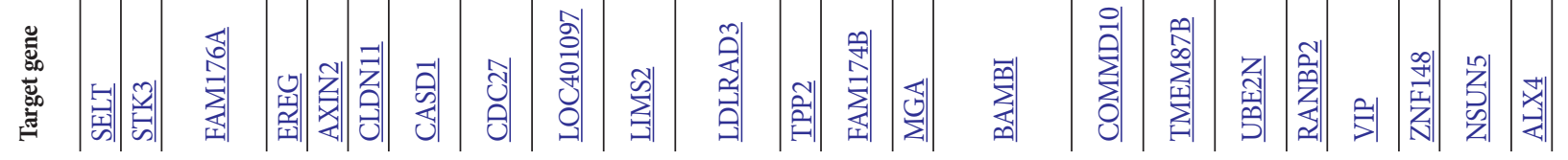




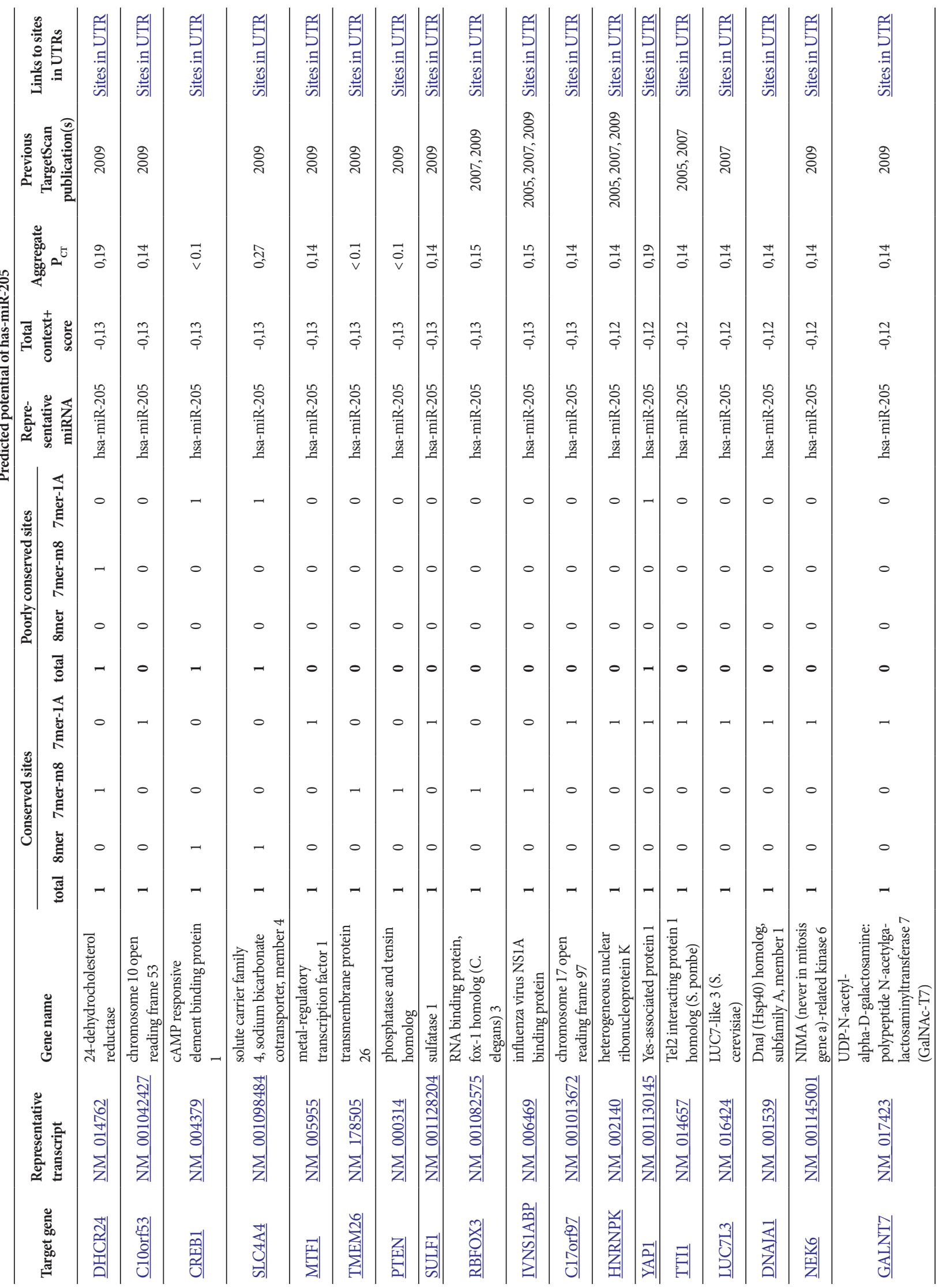




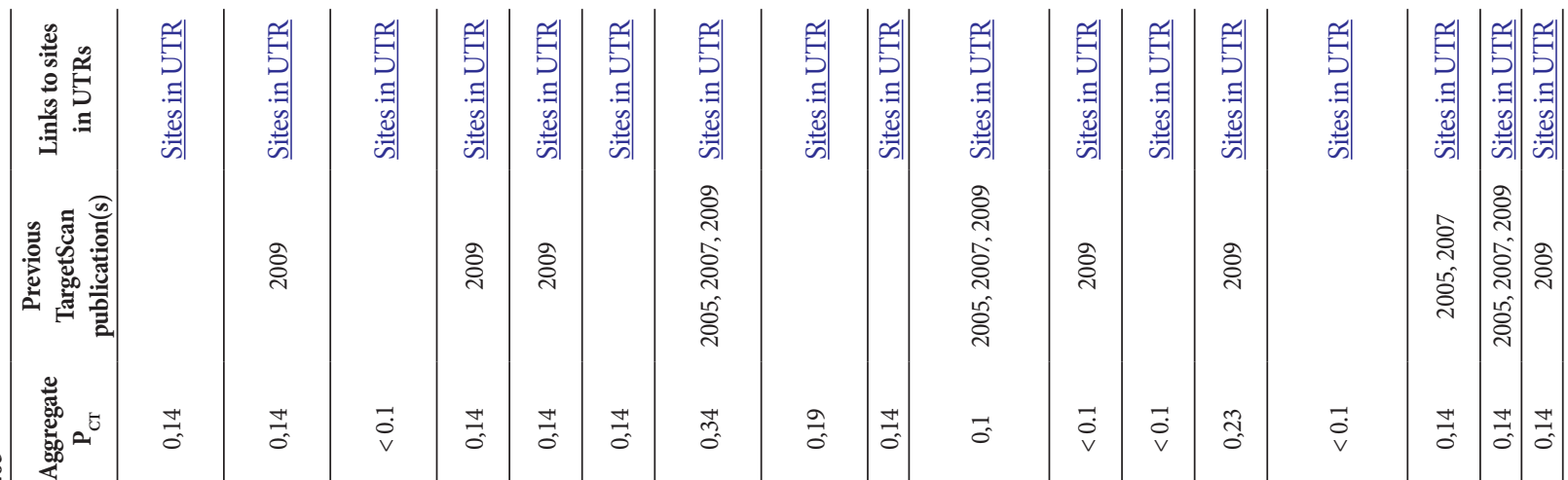

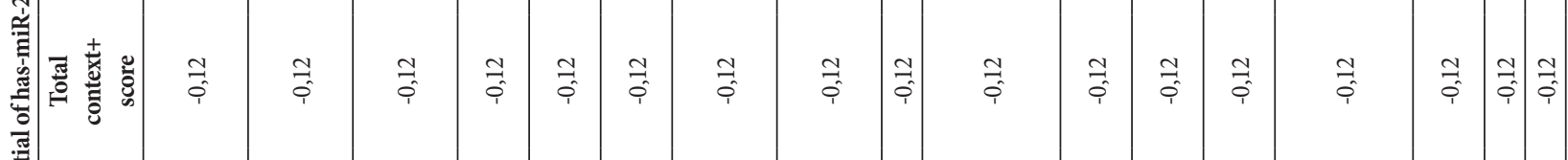

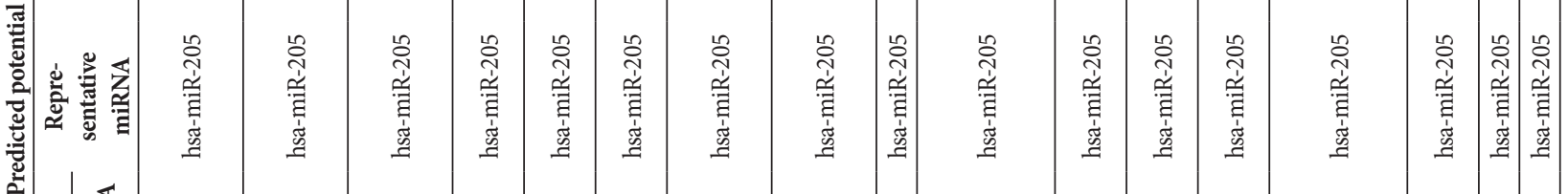

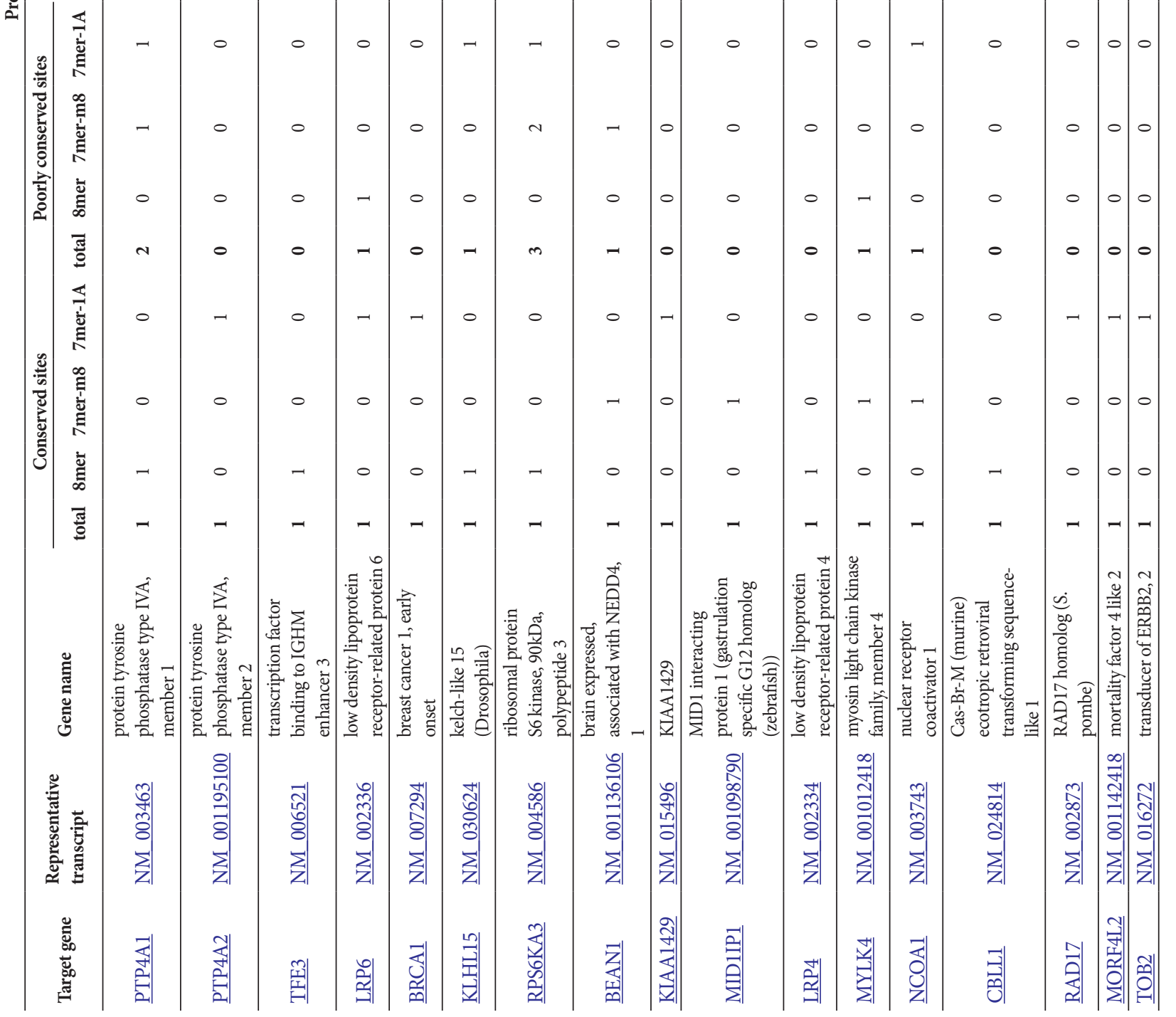




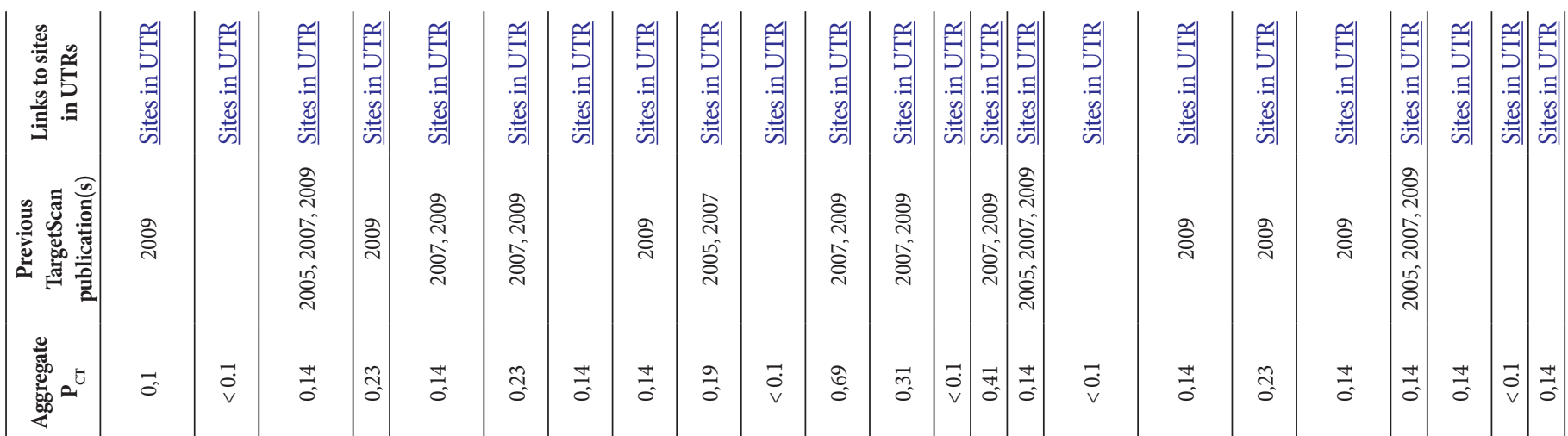

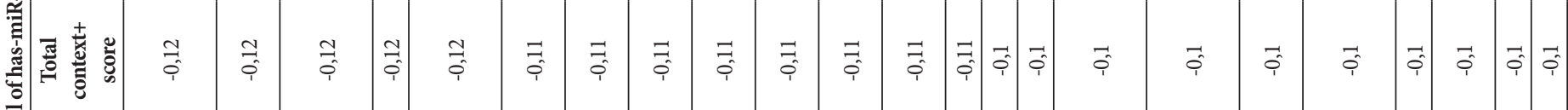

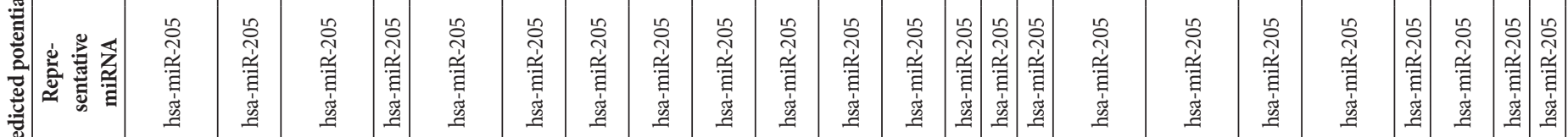
气

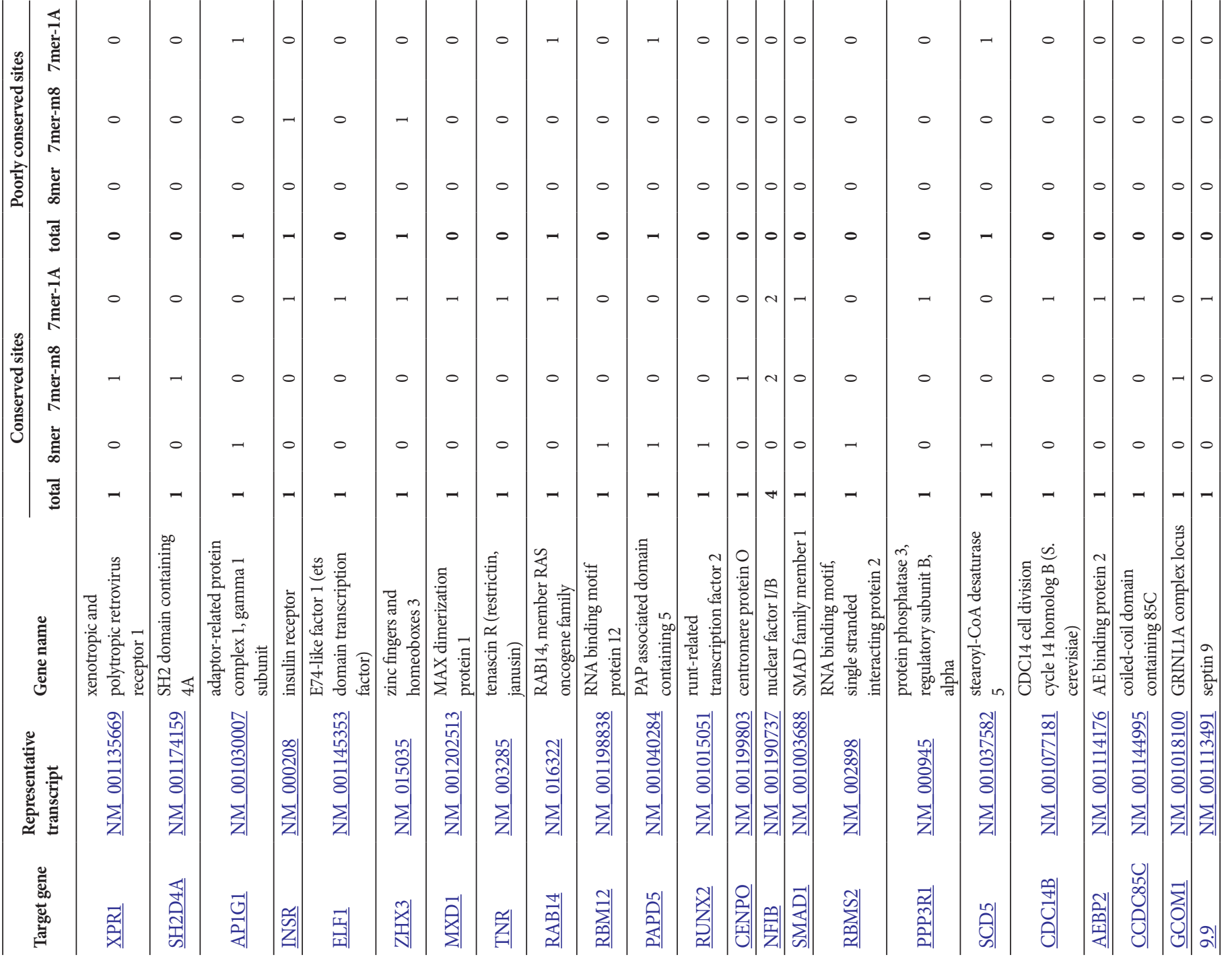




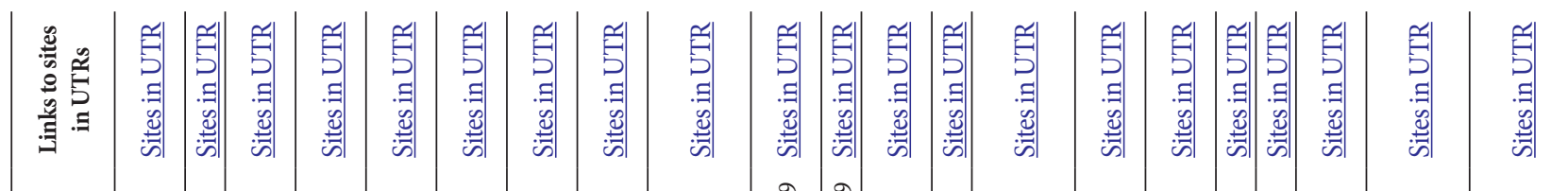

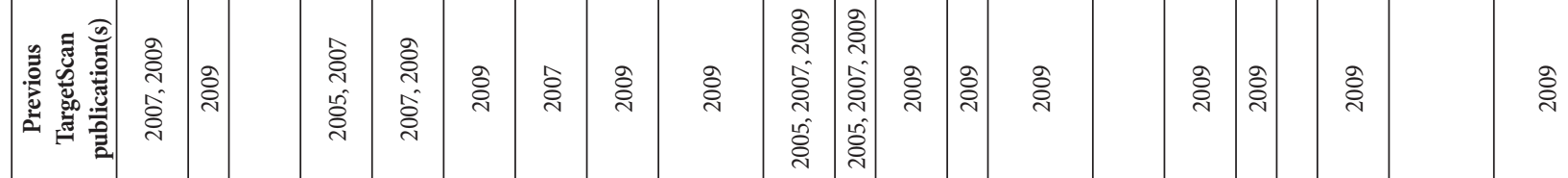

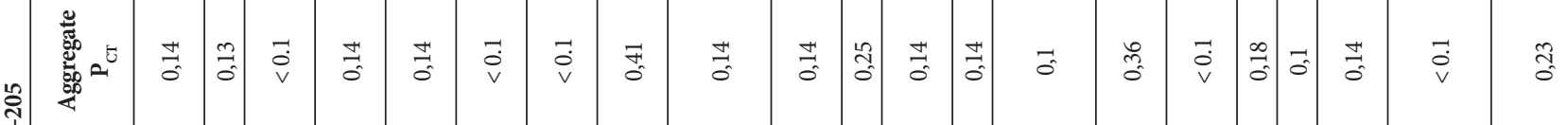
岁

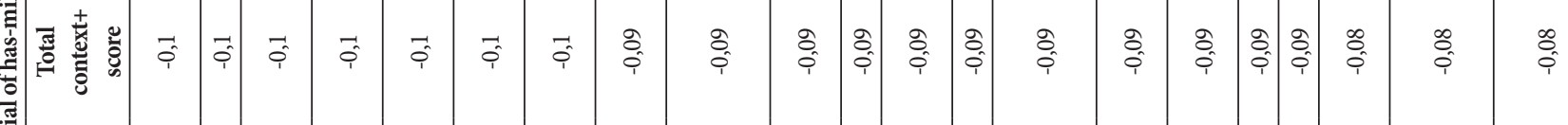

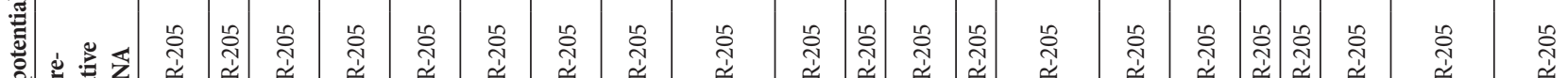

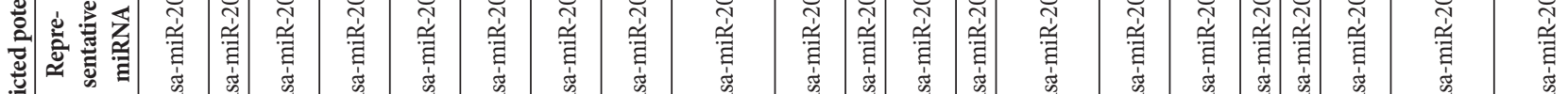

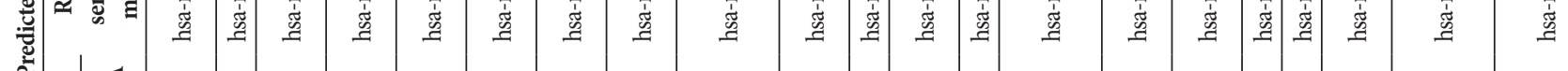

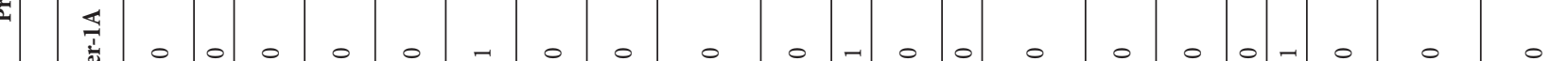

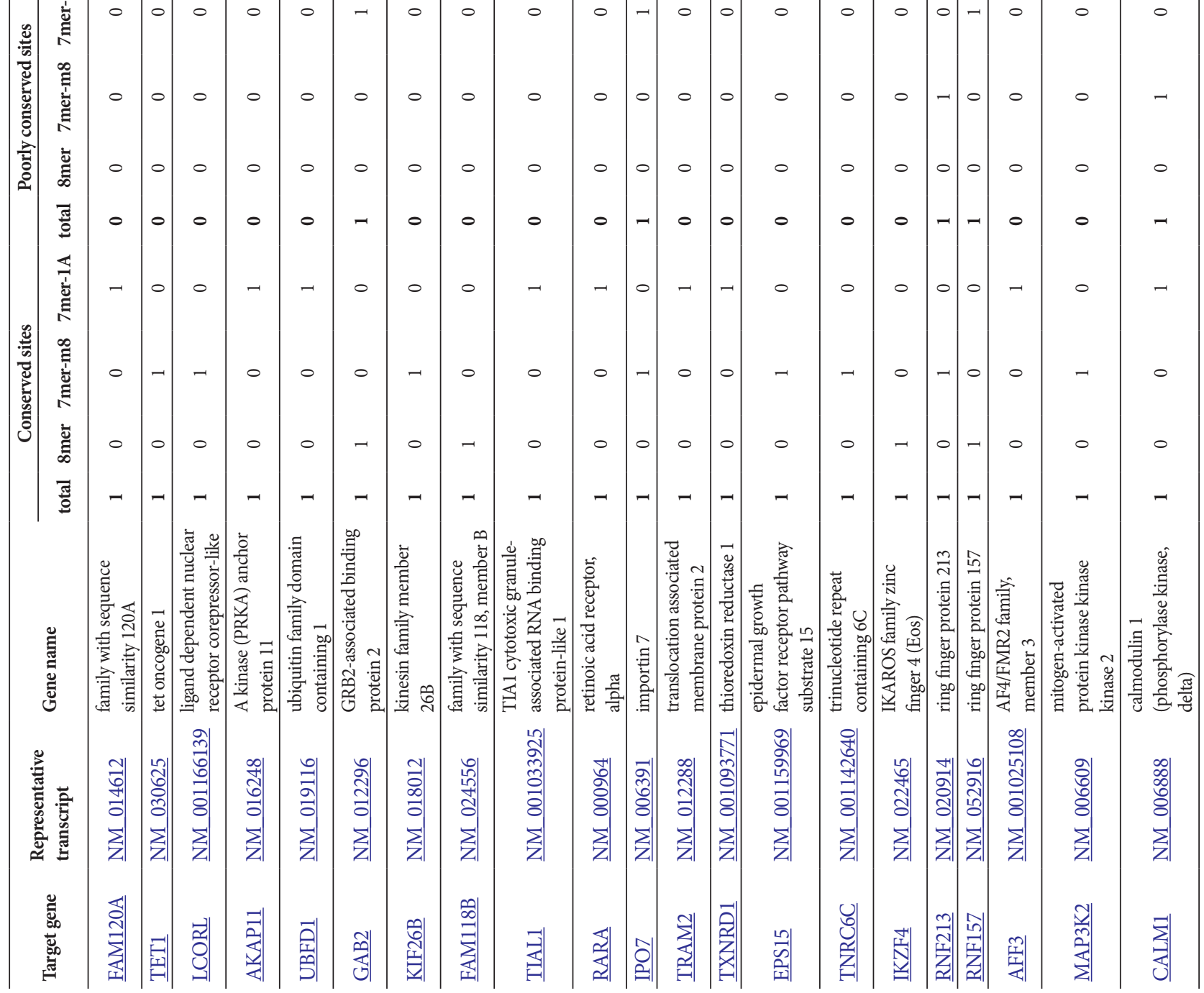




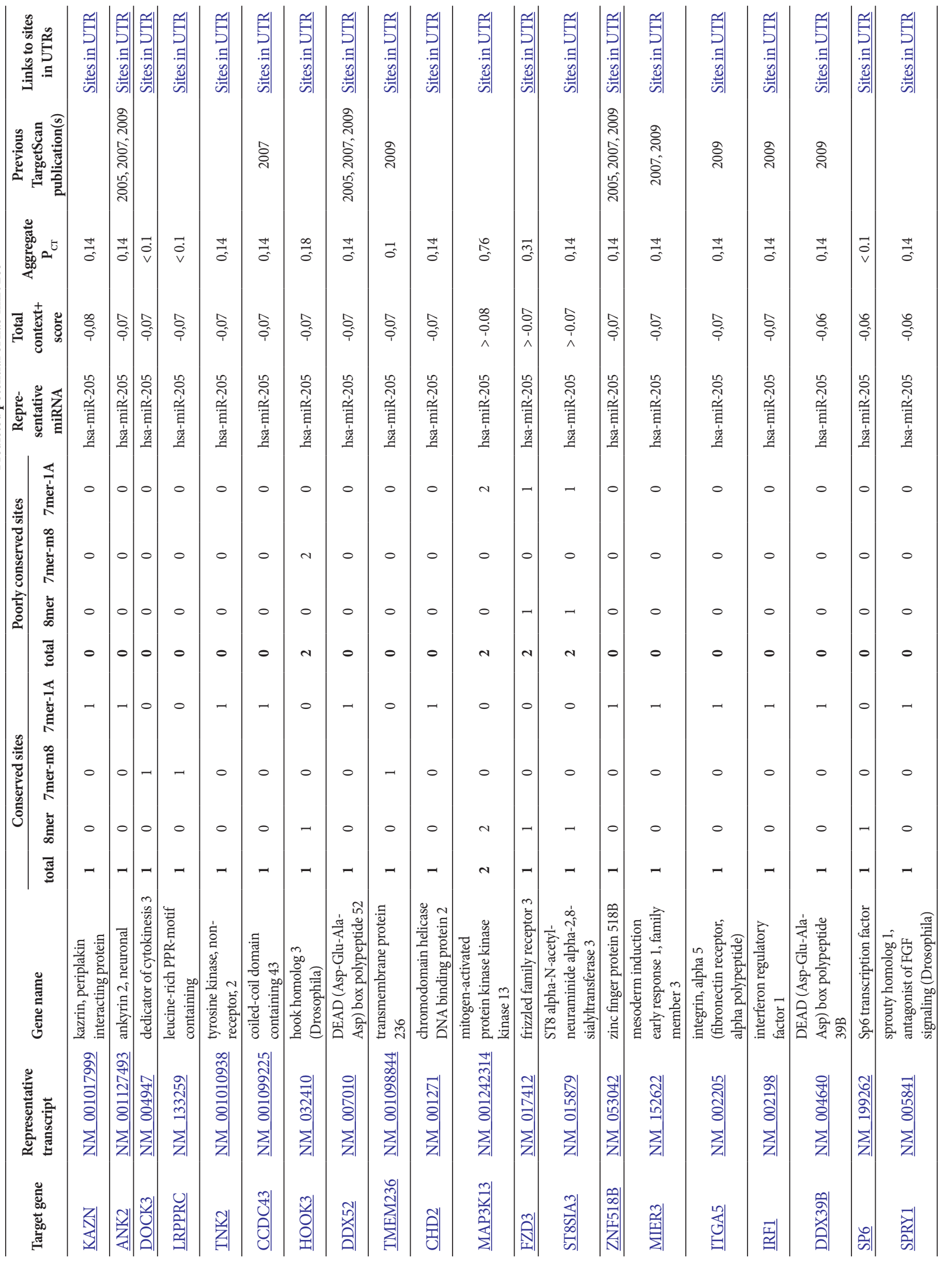




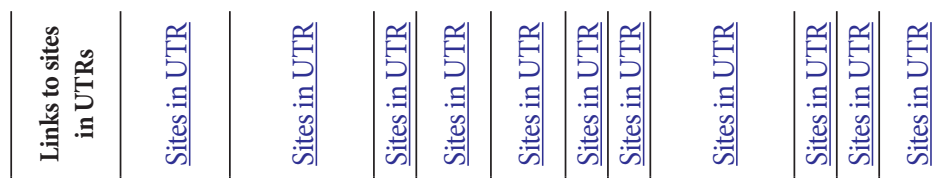

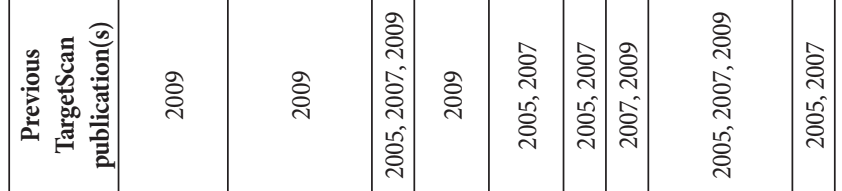

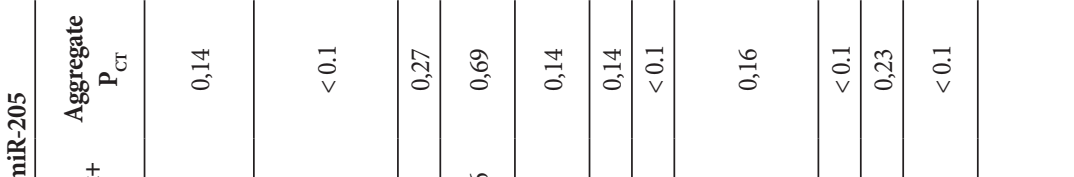

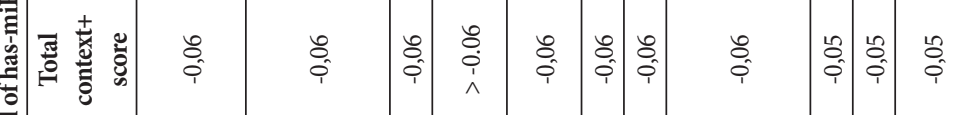

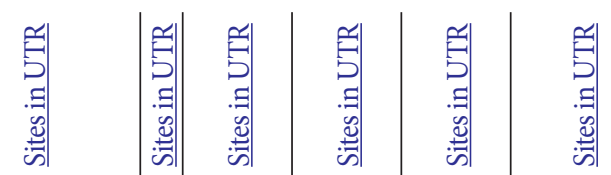

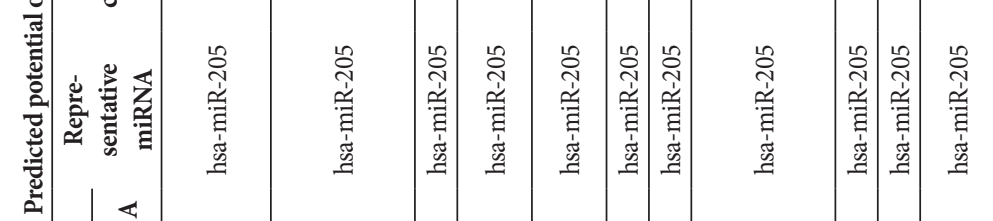

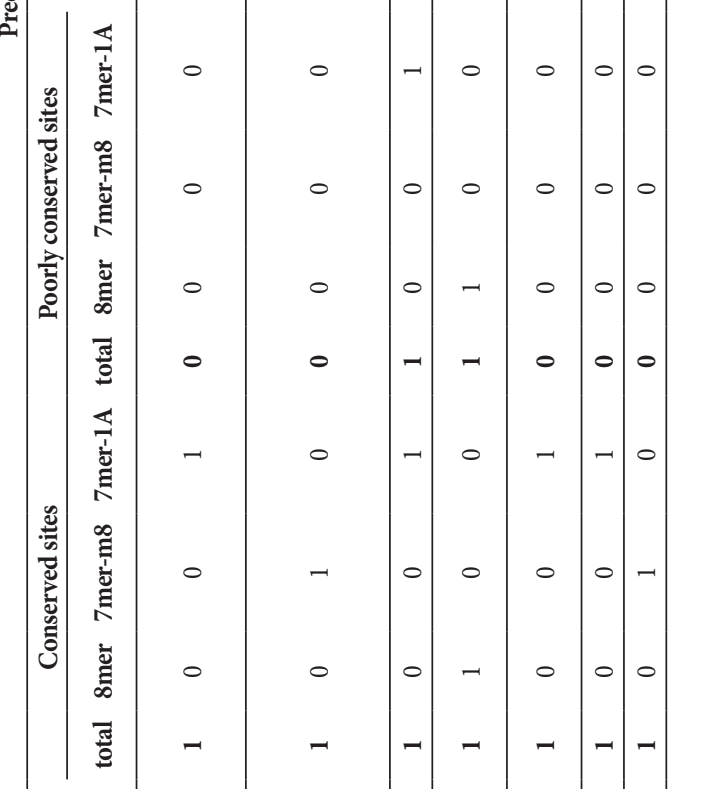

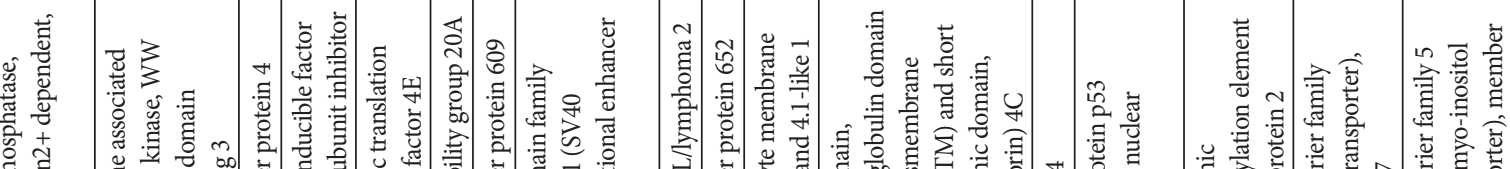

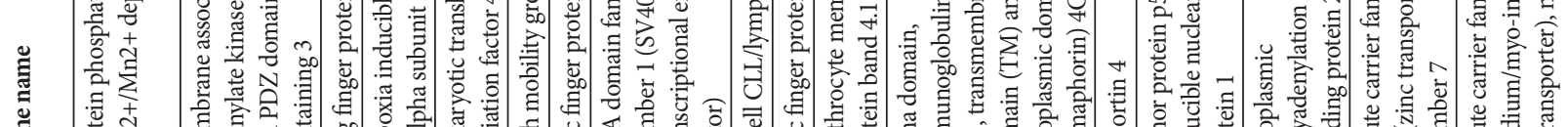

至

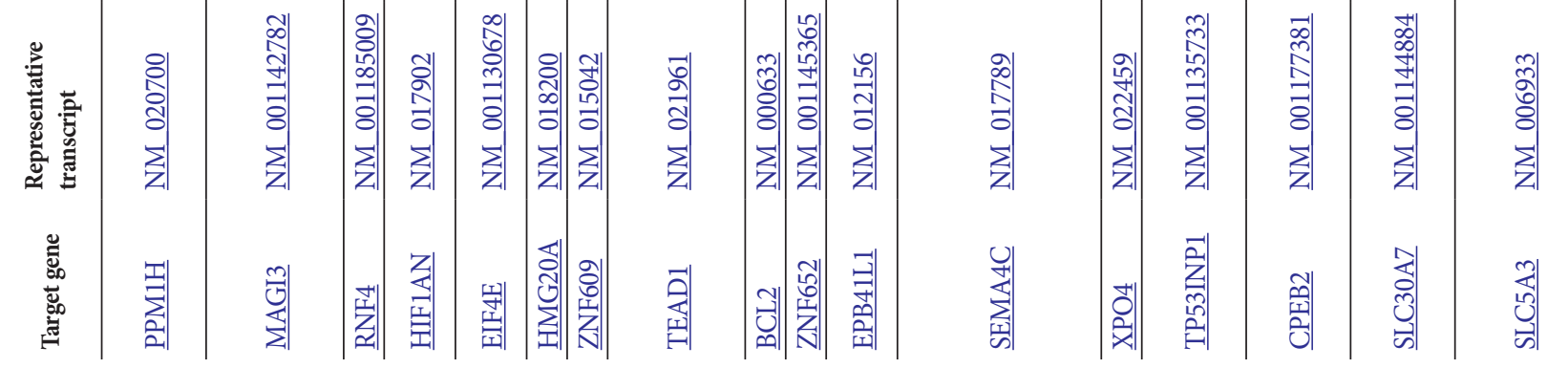




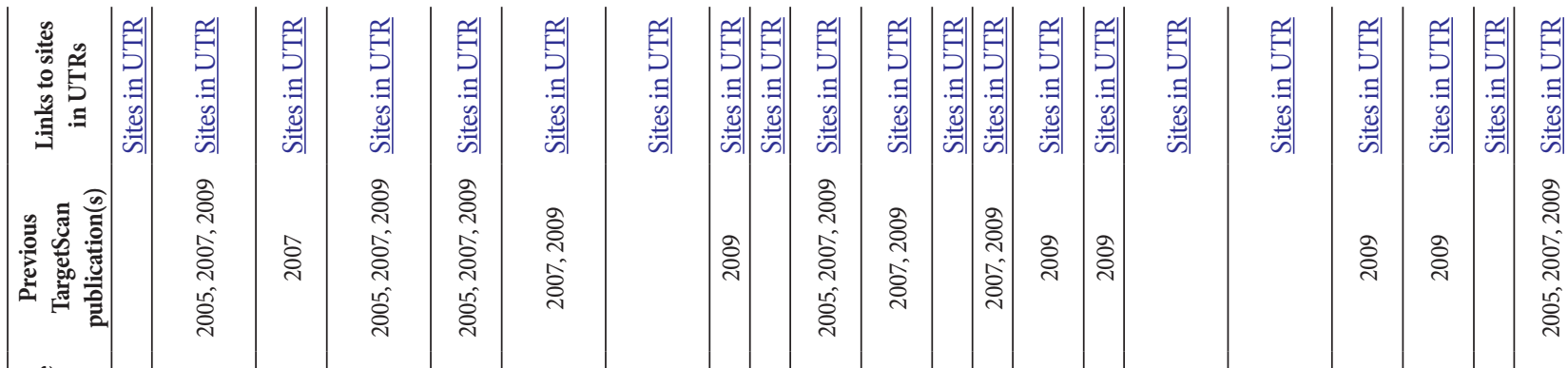

西

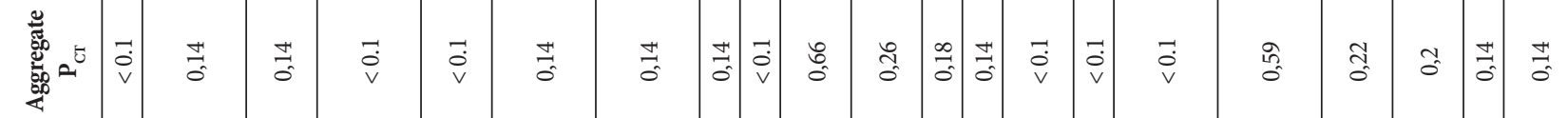

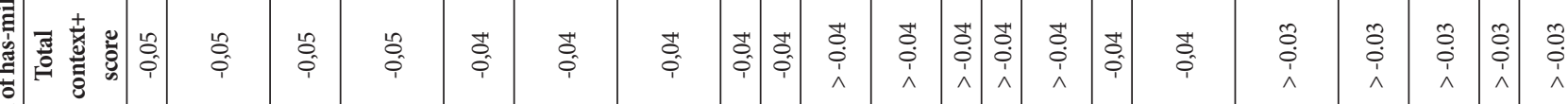

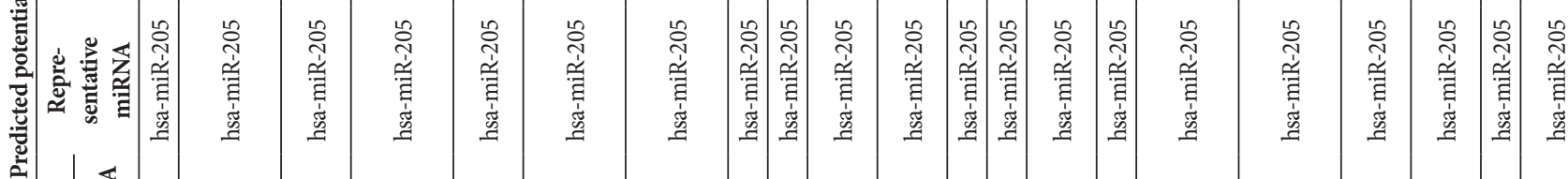

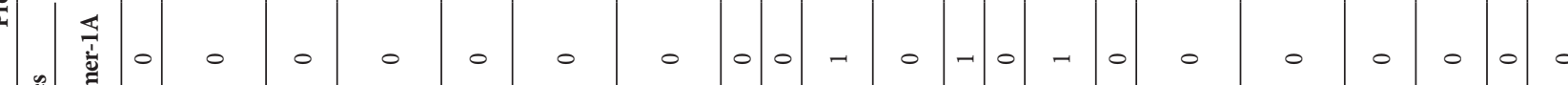
.

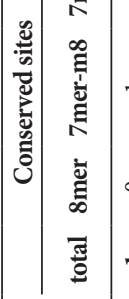

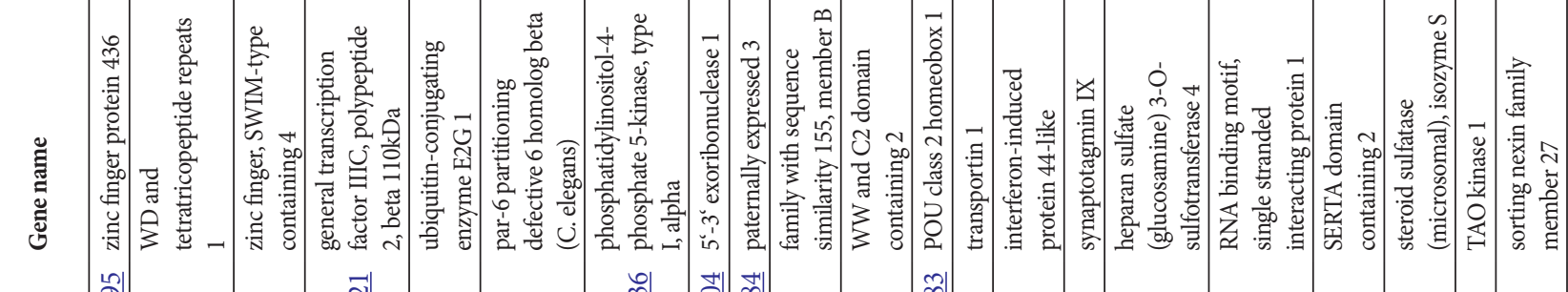

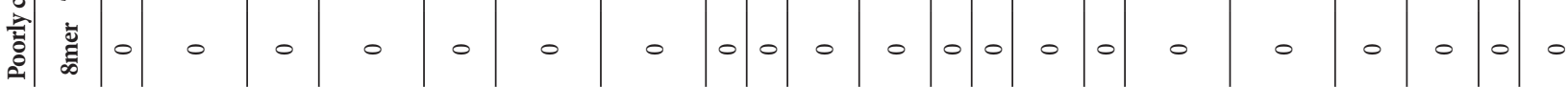

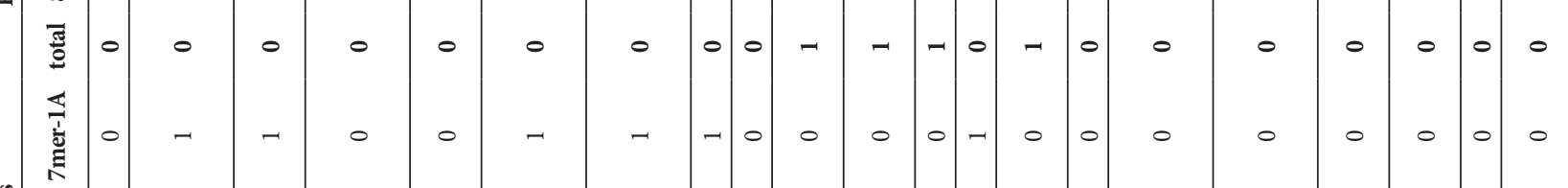

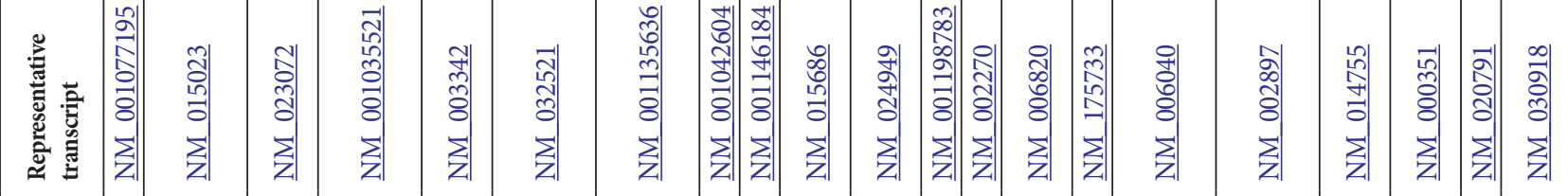

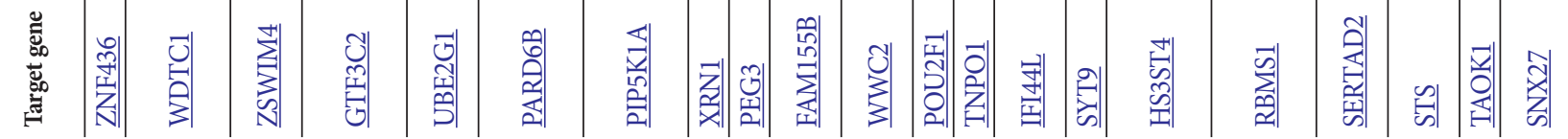




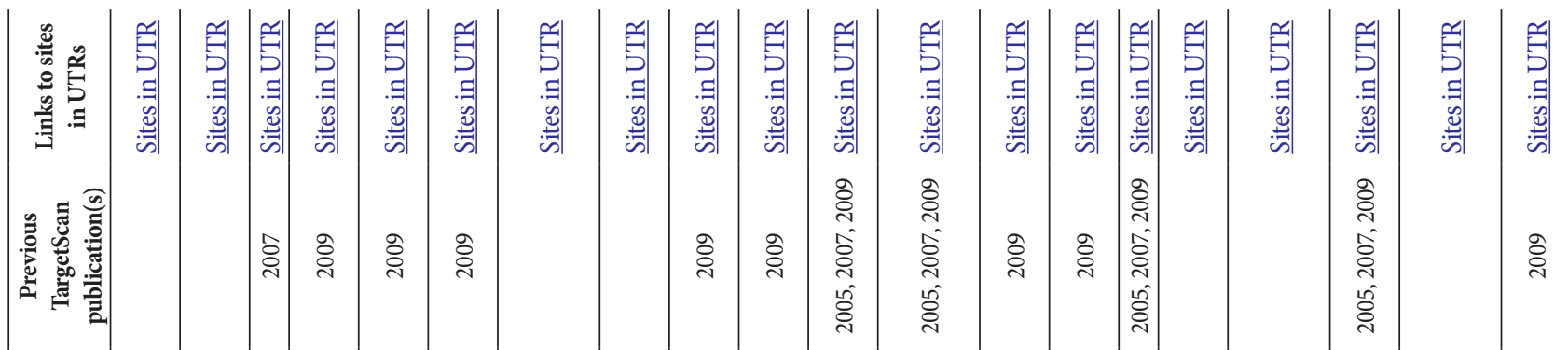

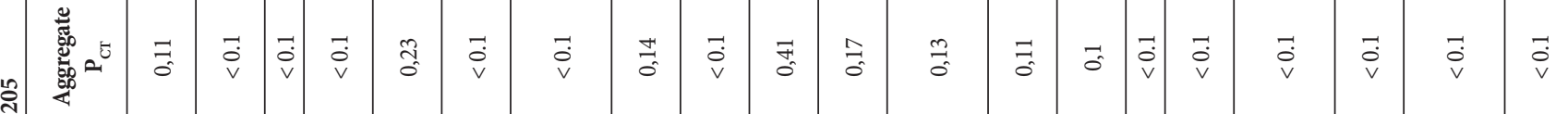

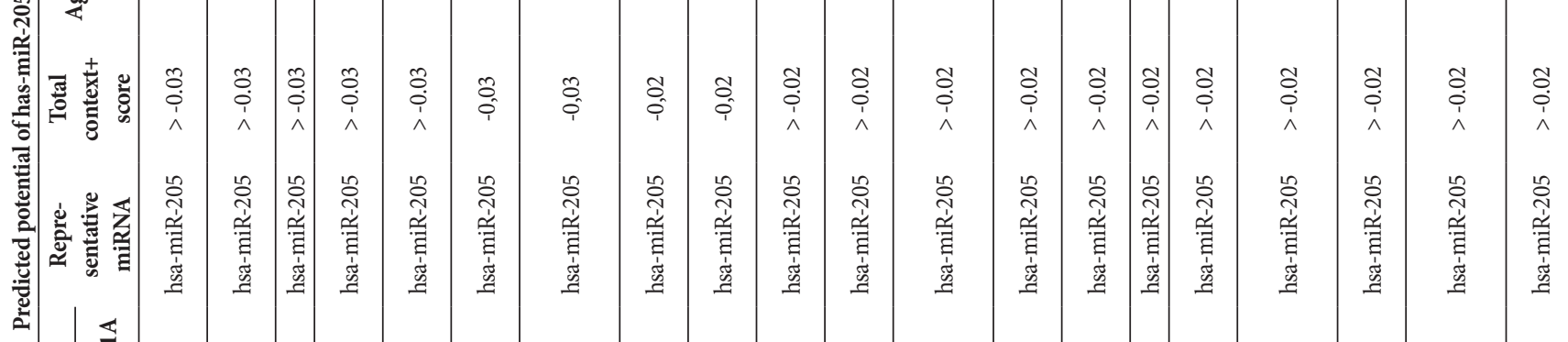

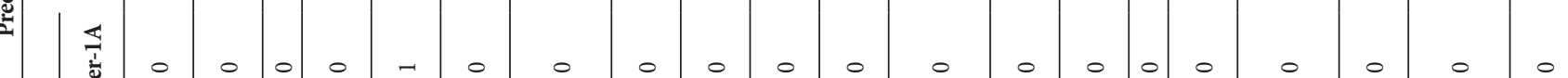

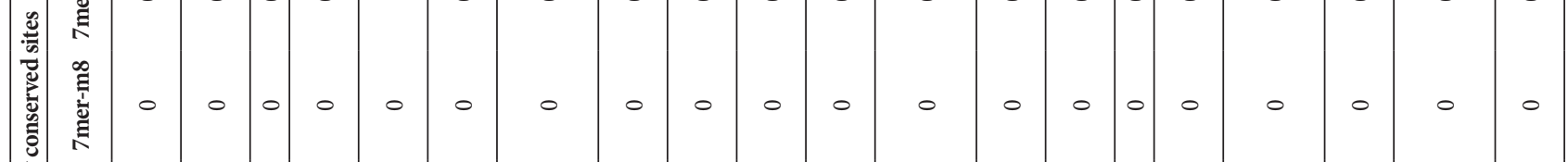

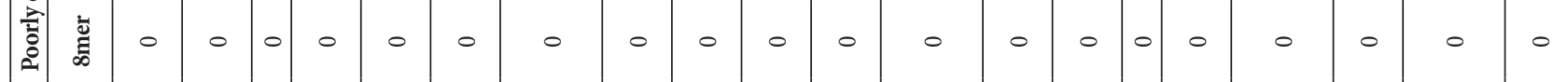

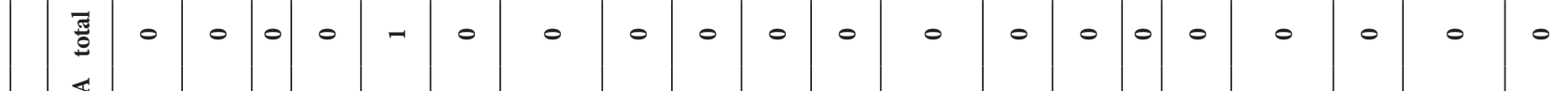
\begin{tabular}{|l|l|l|l|l|l|l|l|l|l|l|l|l|l|l|l}
\hline \\
畜
\end{tabular}

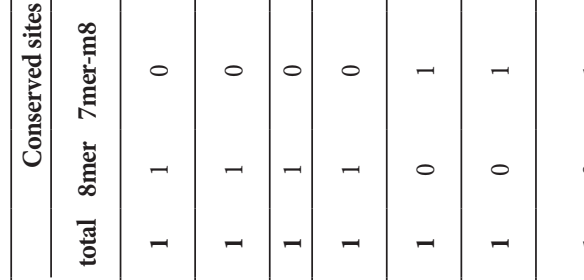

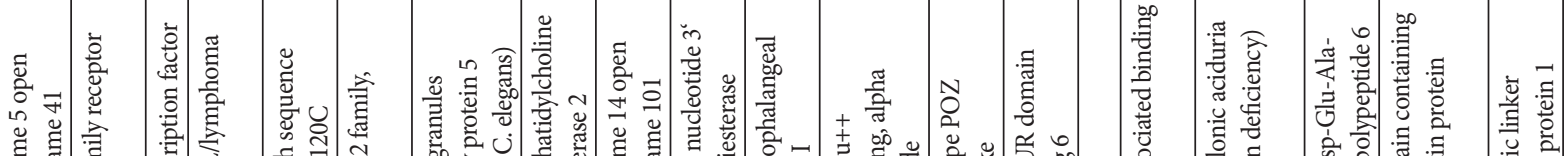

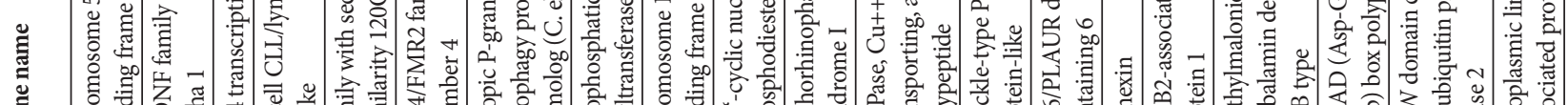
吾

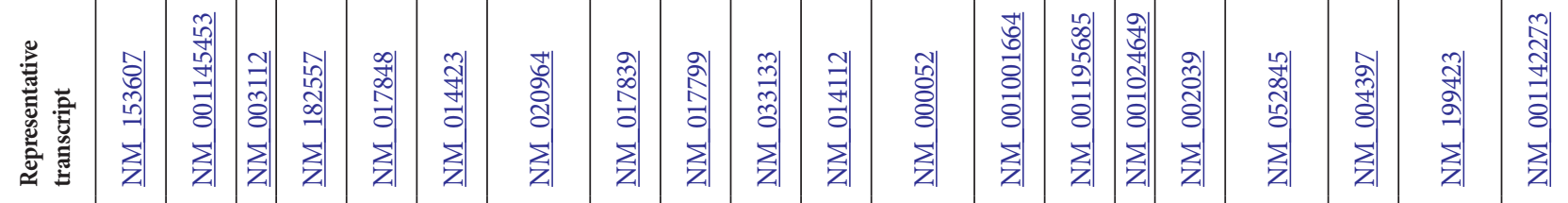

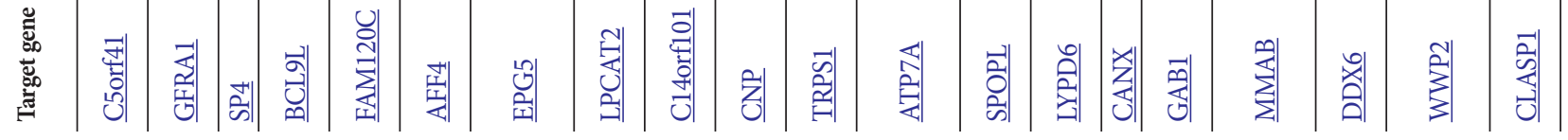




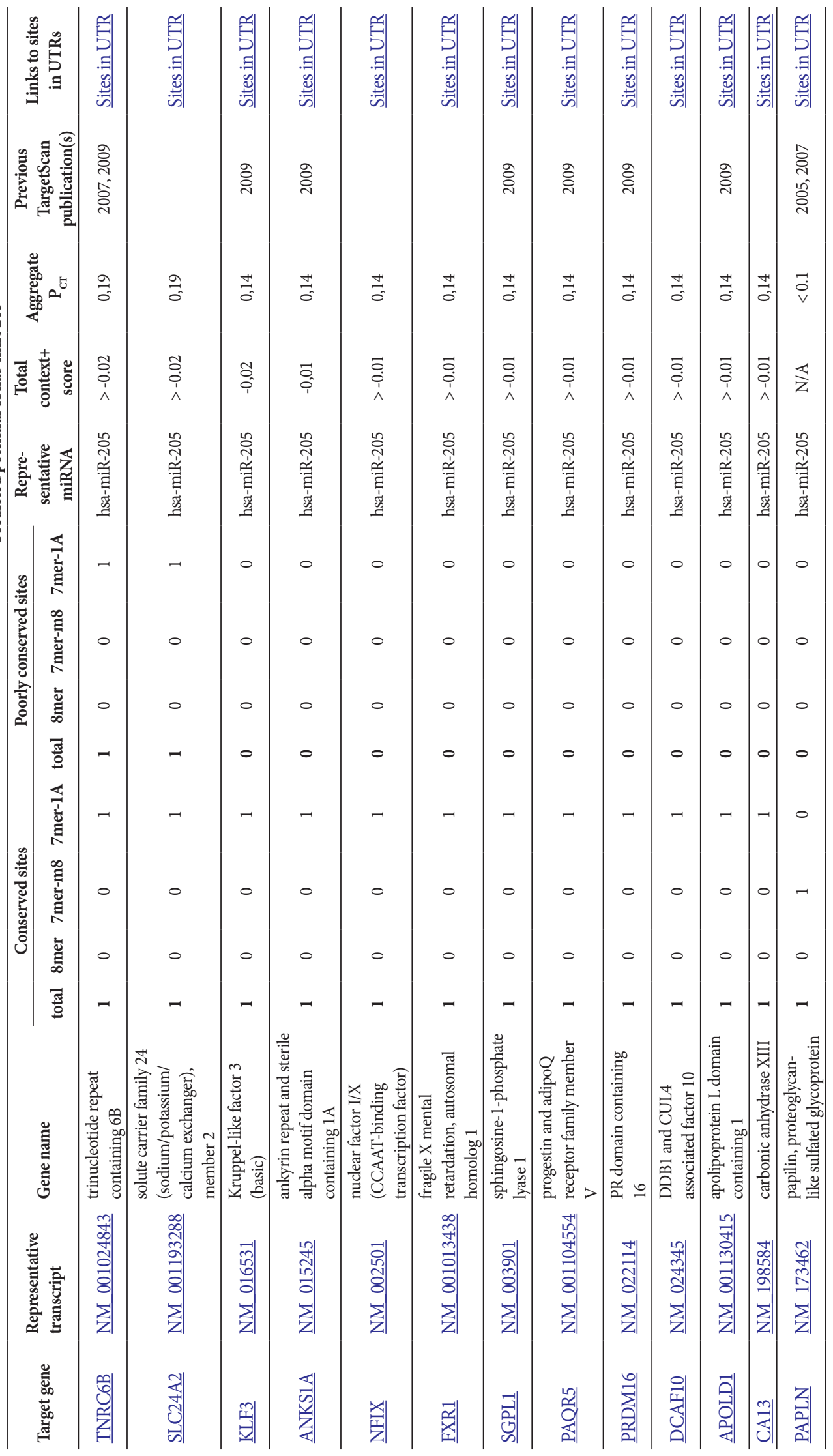

